\title{
ENGINEERING EXPERIENCE AT BROOKHAVEN NATIONAL LABORATORY IN HANDLING FUSED CHLORIDE SALTS
}

\section{C.J. Raseman, H. Susskind, G. Farber, W.E. McNulty, and F.J. Salzano}

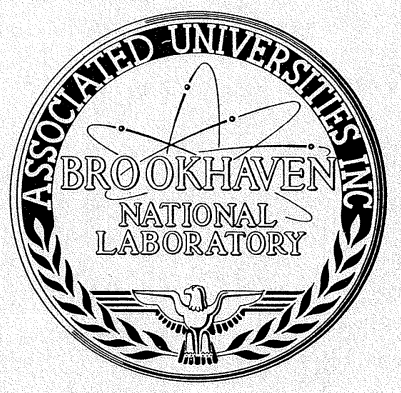

June 1960

\author{
BROOKHAVEN NATIONAL LABORATORY \\ Associated Universities, Inc. \\ under contract with the \\ United States Atomic Energy Commission
}




\title{
ENGINEERING EXPERIENCE AT BROOKHAVEN NATIONAL LABORATORY IN HANDLING FUSED CHLORIDE SALTS
}

\author{
C.J. Raseman, H. Susskind, G. Farber, W.E. McNulty, and F.J. Salzano
}

June 1960

BROOKHAVEN NATIONAL LABORATORY

Upton, N.Y. 


\section{E G A L N O T I C E}

This report was prepared as an account of Government sponsored work. Neither the United States, nor the Commission, nor any person acting on behalf of the Commission:

A. Makes any warranty or representation, expressed or implied, with respect to the accuracy, completeness, or usefulness of the information contained in this report, or that the use of any information, apparatus, method, or process disclosed in this report may not infringe privately owned rights; or

B. Assumes any liabilities with respect to the use of, or for damages resulting from the use of any information, apparatus, method, or process disclosed in this report.

As used in the above, "person acting on behalf of the Commission" includes any employee or contractor of the Commission, or employee of such contractor, to the extent that such employee or contractor of the Commission, or employee of such contractor prepares, disseminates, or provides access to, any information pursuant to his employment or contract with the Commission, or his employment with such contractor.

\section{PRINTED IN USA}

PRICE 75 GENTS

Available from the Office of Technical Services, Department of Commerce

Washington 25, D.C. 


\section{SUMMARY}

Two fused chloride salt eutectics, binary LiCl$\mathrm{KCl}$ and ternary $\mathrm{NaCl}-\mathrm{KCl}-\mathrm{MgCl}_{2}$, have been used extensively in fuel processing studies at Brookhaven National Laboratory as part of the Liquid Metal Fuel Reactor research and development program. This report summarizes the results of the engineering work done at Brookhaven since 1950. Because the program was terminated on short notice, certain phases were not completed; several components that were designed and built were operated only for a short period or in some cases not at all.

Since the fused chloride eutectics are subject to rapid reaction with atmospheric moisture, all handling in the liquid state must be done in an inert atmosphere. In addition, since corrosion by the fused salts is greatly enhanced by the presence of oxidizing impurities, all equipment for use in salt preparation or experimental work must be thoroughly cleaned and tested for leak tightness before use. Generally, 347 S.S. was used as the container material.

It has been demonstrated that fused chloride salt technology is sufficiently developed that loops and other experimental equipment can be designed and operated at $500^{\circ} \mathrm{C}$ with a high degree of confidence. The equipment, which was operated for many hundreds (in some cases thousands) of hours, included a large forced circulation loop and many thermal convection loops and tanks. Another large salt loop was designed and built as part of a liquid metal - fused salt continuous processing experiment, but not yet operated.

The specifications used at Brookhaven for the fabrication, cleaning, and testing of equipment for salt service are described. All-welded systems, welded by the usual inert-arc procedures, are preferred, but ring-type joint, stainless steel, flanged connections have also been found satisfactory, mainly for connecting melt tanks to experimental equipment and for mounting orifice flowmeters. The surfaces of equipment to be used with fused salts have been cleaned satisfactorily prior to assembly by several different methods, but only one, sandblasting with 30 to 40 -mesh sand at a pressure of 60 psig, was found applicable to all types of equipment. Radiography was used to check all welds that were to be in contact with fused salt for flaws and, during operation, to locate and determine the cause of any malfunction. Repairs could be made on piping that had previously been in contact with fused salt.
A number of components were tested at the normal operating temperature of $500^{\circ} \mathrm{C}$, including pumps, valves, agitators, sightports, samplers, and filters. One small and three large pumps were tested. A small 1/12-hp, axial flow unit was operated in a corrosion test loop for $1000 \mathrm{hr}$ at a flow rate of $3.2 \mathrm{gpm}$ and a head of $0.5 \mathrm{ft}$. Two larger sump-type canned centrifugal pumps, rated for 11 gpm and 45-ft head and $7 \mathrm{gpm}$ and 17 -ft head, were operated for periods of 1034 and $512 \mathrm{hr}$, respectively. Difficulties were encountered with the first pump involving splashing of salt, which caused shorting of liquid level resistance probes, and shaft hangup. These problems were solved in the second unit, built at Brookhaven, by enlarging the gas space in the sump, adding baffles around the impeller shaft to minimize salt splashing, and placing the liquid level probes in a vessel side arm to prevent probe shorting. A canned-rotor type of centrifugal pump, on the other hand, could not be operated successfully.

Bellows sealed, 1/2-in.-IPS, Y-pattern globe valves gave good service in both static and circulating salt systems. Commercial needle valves did not. A needle valve was designed and built at Brookhaven but was not tested with fused salt.

Salt samples were usually taken in graphite cups by the thief method. When rapid sampling was required, up to 10 salt samples could be obtained in quick succession from a circulating stream with a special in-line sampler, which was built and tested but not used.

Both stationary and movable resistance-type liquid level probes were used extensively. They were reliable so long as the salt surface remained quiescent, otherwise splashing and short-circuiting occurred. This difficulty was overcome by locating the probes in a vessel side arm.

Nullmatic, pilot operated, pressure transmitters gave good service. They were used in conjunction with both orifice and Venturi flowmeters.

A procedure is described for preparing pound quantities of pure eutectics, which, in the case of the ternary eutectic, differs from that used in preparing gram quantities. Both eutectics had to be pretreated with a $\mathrm{Bi}-\mathrm{Mg}-\mathrm{U}$ solution to remove oxidizing impurities before use in corrosion and processing experiments.

The results of physical property measurements on the two eutectics, made at Brookhaven and elsewhere, are included in this report. 


\section{CONTENTS}

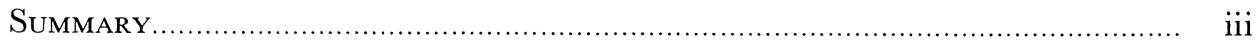

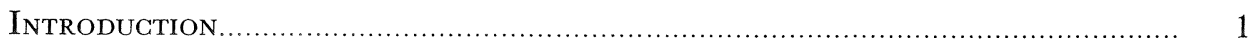

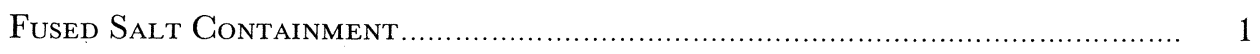

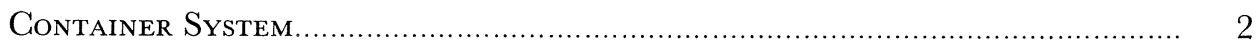

Piping System Design........................................................................ 2

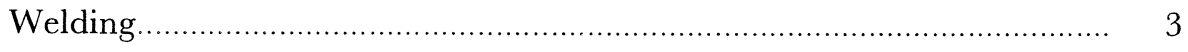

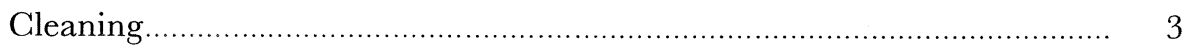

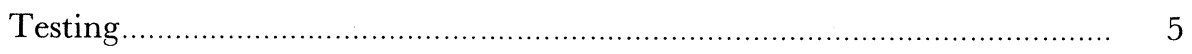

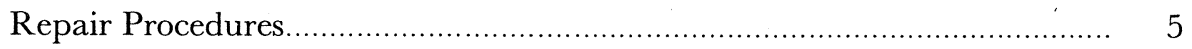

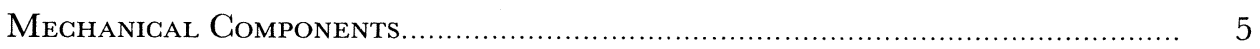

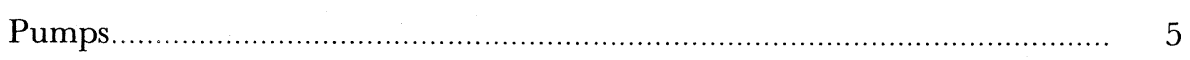

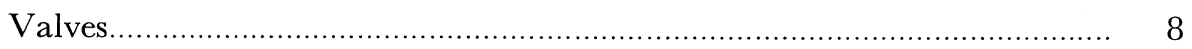

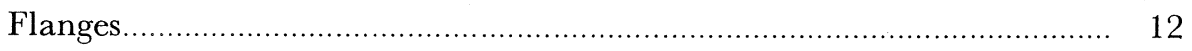

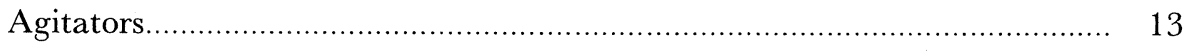

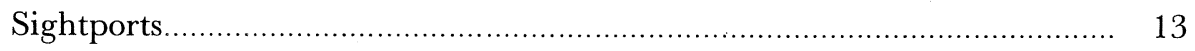

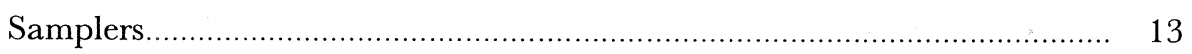

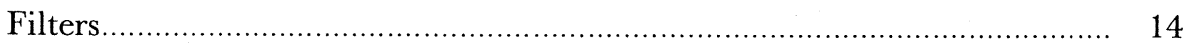

INERT GAS SYSTEM

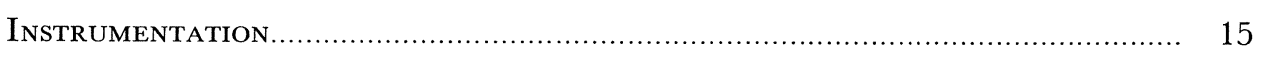

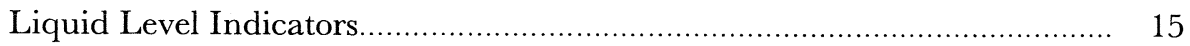

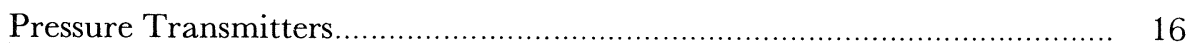

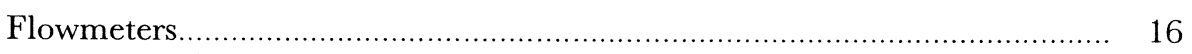

Temperature Measurement.............................................................. 17

Salt Preparation and Handling ................................................................... 17

Preparation of Salts........................................................................... 17

Salt Transfer to Experimental Equipment.................................................. 21

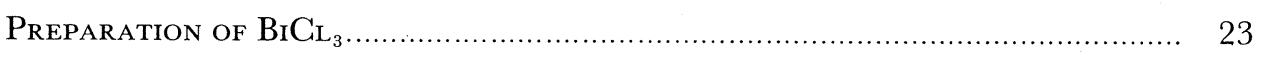

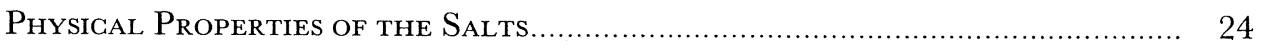

Binary Eutectic .................................................................................. 24

Ternary Eutectic ......................................................................... 25

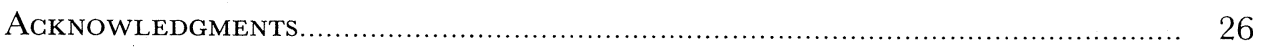

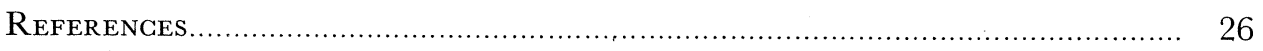




\section{FIGURES}

1. A typical fused salt vessel wrapped with flexible 20-gauge nichrome heater wire................... 2

2. Axial flow salt pump with magnetically coupled, $1 / 12$-hp, variable speed, ac-dc motor........... 4

3. Calibration curve for the axial flow salt pump................................................................. 5

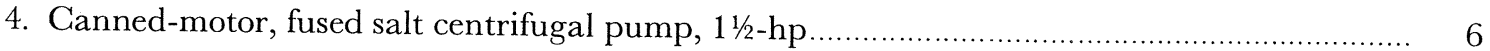

5. Impeller for the 11/2-hp, canned-motor, fused salt centrifugal pump ....................................... 6

6. Calibration curve for the $1 \frac{1}{1} 2$-hp, canned-motor, fused salt centrifugal pump........................ 7

7. Fused salt centrifugal pump, 3-hp, with variable speed, dc drive and magnetic coupling..... 8

8. Impeller for the 3-hp, variable speed, fused salt centrifugal pump ....................................... 9

9. Magnetic coupling for the 3-hp, variable speed, fused salt centrifugal pump........................... 9

10. Calibration curve for the 3-hp, variable speed, fused salt centrifugal pump............................ 9

11. Canned-rotor, fused salt centrifugal pump, 3-hp ........................................................... 10

12. Typical 1/2-in.-IPS, 300-lb, Y-pattern globe valve for fused salt service ................................. 11

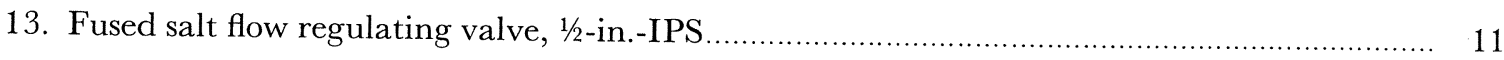

14. Calibration curve for the $1 / 2$-in.-IPS, fused salt flow regulating valve ................................... 12

15. Magnetically coupled agitator with fractional-hp, ac-dc, variable speed drive ...................... 12

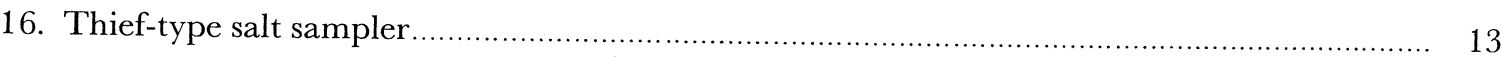

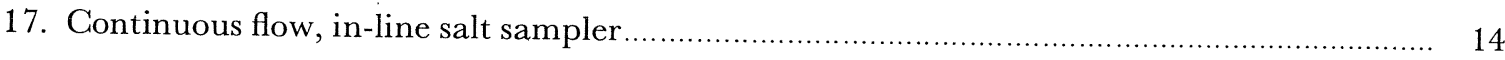

18. Sample cup holder carriage for in-line salt sampler........................................................ 15

19. Nullmatic, pilot operated, fused salt pressure transmitter .............................................. 16

20. Low salt flow, orifice flowmeter installation ................................................................. 16

21. Low salt flow, orifice flowmeter calibration curve ........................................................... 16

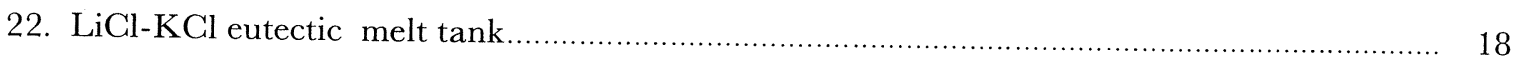

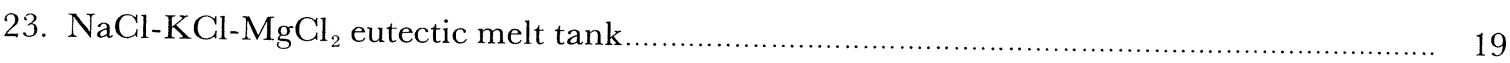

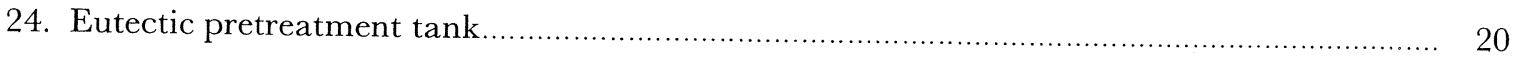

25. Equipment arrangement for loading fused salt into Pyrex tubes............................................ 22

26. Equipment arrangement for discharging salt from Pyrex tubes.......................................... 22

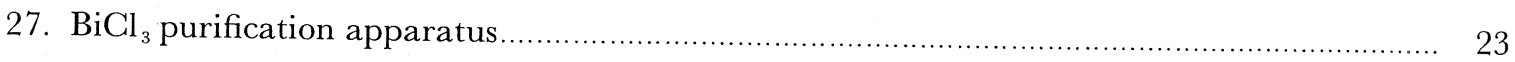

28. Basket arrangement for adding $\mathrm{BiCl}_{3}$ to fused salt ......................................................... 24 


\section{ENGINEERING EXPERIENCE AT BROOKHAVEN NATIONAL LABORATORY IN HANDLING FUSED CHLORIDE SALTS}

\section{INTRODUCTION}

Two fused chloride salt eutectics, binary LiCl$\mathrm{KCl}\left(59\right.$ and 41 mole $\%$, respectively; m.p. $351^{\circ} \mathrm{C}$ ) and ternary $\mathrm{NaCl}-\mathrm{KCl}-\mathrm{MgCl}_{2}(30,20$, and 50 mole \%, respectively; m.p. $396^{\circ} \mathrm{C}$ ), have been used extensively in fuel processing studies at Brookhaven National Laboratory in connection with the Liquid Metal Fuel Reactor research and development program. Early studies by Bareis ${ }^{1}$ indicated that liquid-liquid extraction with fused salts would be an advantageous method for processing the reactor fuel, a dilute solution of $\mathrm{U}, \mathrm{Mg}, \mathrm{Zr}$ (and fission products) in $\mathrm{Bi}$. A number of fused chloride salts immiscible in $\mathrm{Bi}$ were available for selection as solvents. Mixtures of these chlorides could also be obtained which have reasonably low melting points and good stability at high temperatures and are nontoxic. A process was proposed by Dwyer et al. ${ }^{2}$ for decontamination of the fuel and control of its $U$ concentration, and Wiswall et al. ${ }^{3-5}$ showed the mechanism to be a simple chlorination of the fission products (primarily those in groups IA, IIA, and IIIA of the Periodic Table and the rare earths) followed by solution of the resulting chlorides in the salt phase at $500^{\circ} \mathrm{C}$. These fission products constitute $\approx 55 \%$ of all nonvolatile fission products, especially those with large neutron absorption cross sections. This chlorination may be accomplished either by controlling the oxidation potential of the system with a $\mathrm{Mg}-\mathrm{Mg}^{++}$ buffer solution or by adding $\mathrm{BiCl}_{3}$ in stoichiometric amounts to the fuel solution.

The eutectic of $\mathrm{LiCl}-\mathrm{KCl}$ was the first chloride salt mixture to be selected, but only to establish the validity of the process. It was not suitable for processing because (1) Li metal, one of the reaction products, transfers to the fuel stream and would become a reactor poison, and (2) the system is very sensitive to small amounts of oxidizing and reducing impurities. It was, therefore, decided to use the ternary $\mathrm{NaCl}-\mathrm{KCl}-\mathrm{MgCl}_{2}$ eutectic in all subsequent processing studies.

The purpose of this report is to present all the available information pertaining to fused chloride salts, principally the ternary eutectic, obtained at Brookhaven since 1950. This includes primarily engineering experience (1) in the preparation of the fused salts in pound-scale batches; (2) in the design and fabrication of equipment to study corrosion, to test components and to study liquid metal - fused salt equilibria and dynamics; and, (3) in the development of techniques to handle the salts at $500^{\circ} \mathrm{C}$. Particular emphasis is placed upon factors peculiar to these salts. They are, for example, subject to rapid reaction with moisture and other reactive impurities. Also, corrosion by the salts is greatly enhanced by the presence of oxidizing impurities. As a result, great care was taken in the preparation and purification of the eutectics and in maintaining an inert and leak-tight environment. The container system, too, was carefully designed and fabricated according to the specifications detailed in this report. Since the size requirements of the fuel processing system were very modest, the largest equipment constructed contained $1 / 2$-in. interconnecting pipe and vessels up to $42 \mathrm{gal}$ in capacity. The various components used for salt service are described and evaluated. All available data on the physical properties of the two salt eutectics are also presented.

It is hoped that this summary will be useful to those interested in the applications of fused salts. Certain phases of the work were not completed because of the curtailment of work on fluid fuel reactor concepts. ${ }^{6}$

\section{FUSED SALT CONTAINMENT}

Corrosion screening tests on potential materials of construction to contain both the binary and ternary eutectics were done as part of the Liquid Metal Fuel Reactor fuel processing program and are reported in detail elsewhere. ${ }^{7} \mathrm{~A}$ few metallic alloys were tested statically for resistance to the $\mathrm{LiCl}-\mathrm{KCl}$ eutectic at $500^{\circ} \mathrm{C}$. Larger-scale tests of 347 and 410 S.S. and $2^{1 / 4} \mathrm{Cr}-1$ Mo steel were conducted in thermal convection loops under a surface temperature difference of $160^{\circ} \mathrm{C}$ for the first two and $53^{\circ} \mathrm{C}$ for the third, with maximum 
surface temperatures of $575^{\circ} \mathrm{C}$ and $505^{\circ} \mathrm{C}$, respectively. Of the materials tested, only 347 S.S. was not attacked in either test.

Screening tests to determine the resistance of a wide range of commercial alloys to the $\mathrm{NaCl}-\mathrm{KCl}$ $\mathrm{MgCl}_{2}$ eutectic were performed in static and tilting furnace capsules. Some ceramics were also tested in static capsules. Larger-scale tests of metallic materials were conducted in 347 and 410 S.S. and $21 / 4 \mathrm{Cr}-1$ Mo steel thermal convection loops, and in a 347 S.S. forced circulation loop. The static tests were conducted isothermally at $500^{\circ} \mathrm{C}$ and the others under a $40^{\circ}$ to $50^{\circ} \mathrm{C}$ bulk temperature difference at the same temperature level. With few exceptions, the ternary eutectic produced little corrosion, and weld areas were not preferentially attacked. The extent of mass transfer attack was negligible in 1000-hr tilting furnace capsule tests, although plugging did occur in a 410 S.S. thermal convection loop after $4000 \mathrm{hr}$ of operation. A wide variety of materials including 1020 mild steel, 21/4 Gr - 1 Mo steel, types 304 (ELC), 310, 316, 347, 430, and 446 stainless steel, 16-1 Croloy, Inconel, Hastelloy "C," Inor-8, Mo, and $\mathrm{Ta}$ is, therefore, available for further investigation and possible use.
It may be significant that little or no $\mathrm{Ni}$ was found in corrodent analyses in any of the tests of Ni-bearing alloys. This fact suggests that further studies might show high $\mathrm{Ni}$ alloys to be superior to all others tested.

To date, 347 S.S. has been used as the principal fused salt container material for the component test loop (Loop M) and for the equipment used in liquid metal - molten salt equilibration studies and large-scale preparation of the binary and ternary salts.

\section{CONTAINER SYSTEM}

\section{Piping System Design}

The binary and ternary eutectics contract upon freezing, which reduces the possibility of rupture of the equipment in the event of a heater circuit failure. It is necessary, however, to pitch all valves and piping to a dump tank to insure complete drainage of the salt in order to avoid possible ruptures upon remelting. Salts may be remelted in vessels and piping if extreme care is taken to melt them progressively from the free surfaces towards the remote areas.

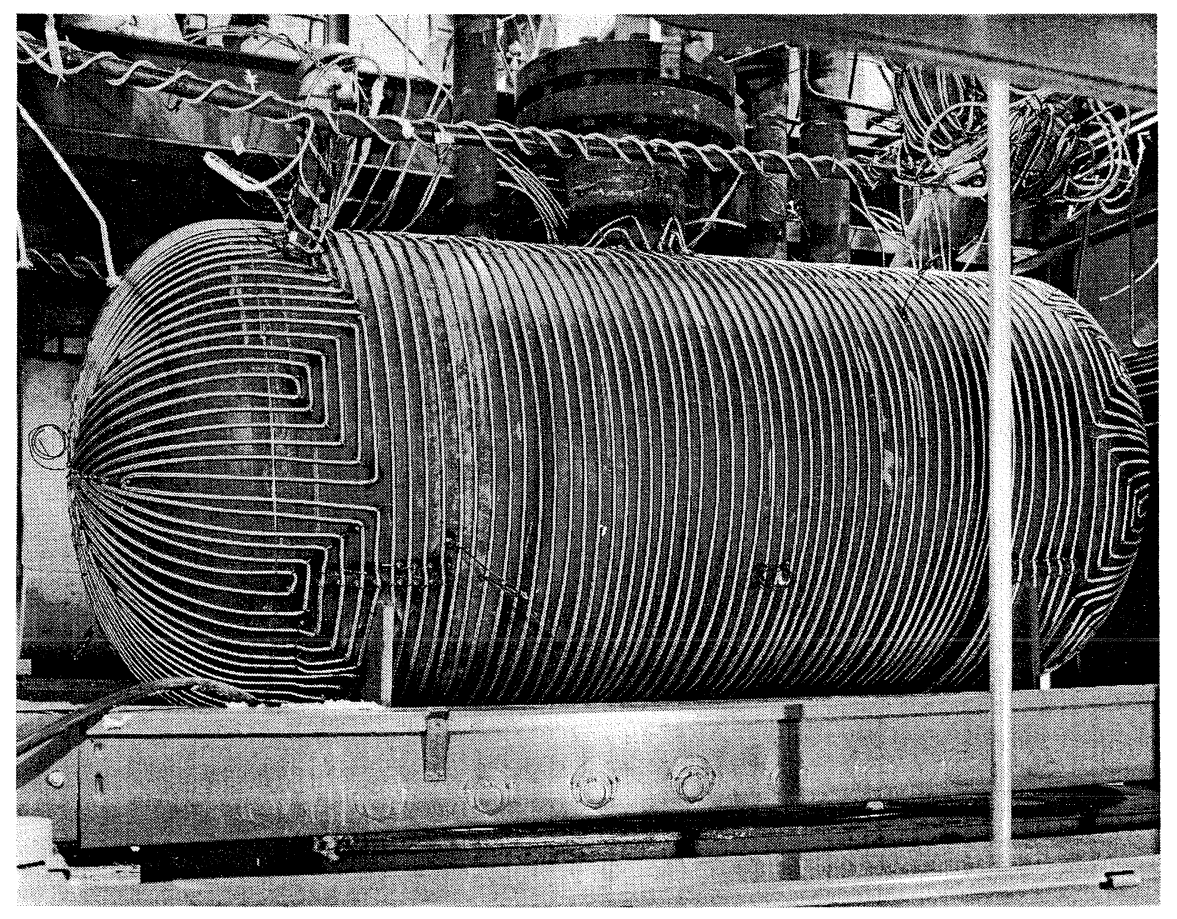

Figure 1. A typical fused salt vessel wrapped with flexible 20-gauge nichrome heater wire. 
The molten salt system is maintained at the normal operating temperature of $500^{\circ} \mathrm{C}$ by electric resistance heaters, usually in the form of flexible nichrome wire, attached to the entire salt system. In applying the heaters to the system, care must be taken to provide for uniform heating of all components. This is best accomplished by using a separate heater circuit on each section that differs in shape or configuration from the adjoining ones. In combined liquid metal - fused salt systems, separate circuits are wound over the piping containing each fluid. A typical vessel wrapped with 20 -gauge nichrome resistance wire is shown in Figure 1.

Molten salts do not react with normal high temperature insulation such as Owens-Corning Kaylo (calcium silicate) and Johns-Manville Superex (calcined diatomaceous silica). These materials, in 2 to 4 -in. thicknesses, are used to insulate the equipment.

Adequate void space should be provided in all vessels, especially those, such as pump sumps, in which surface turbulence occurs. Since the salts melt at a relatively high temperature, splashing will cause salt to deposit on the cooler vessel surfaces, which may result in short-circuiting of liquid level resistance probes and seizing of shafts. To reduce shorting, probe support attachments should be located a considerable distance away from the liquid surface or, better still, in a separate vessel side arm.

The possibility of pressure surges due to the relatively low specific gravity of the salts should be eliminated. A pressure difference of 1 psi will cause the level of the ternary eutectic to change $15 \mathrm{in}$. Consequently, valves should be carefully selected and only those with zero seat leakage should be used for shutoff service, especially as block valves in the loop dump lines.

No cast pipe or fittings can be used for fused salt service because they cannot be made gas-tight, and, after a short period of operation, enough air and moisture from the atmosphere leak in to react with the salt and produce extensive corrosion.

\section{Welding}

An all-welded system is preferred for handling molten salts. Every precaution should be taken to assure that welds are sound and that those in contact with the molten salt are full-penetration welds to eliminate cracks or crevices in the joint. This will help reduce leakage and corrosion. Satisfac- tory welds can be made on 347 S.S., for example, by the inert gas, shielded arc (Heliarc) process. All internal surfaces must be covered with inert gas during welding. Stress-relieving of welds is not necessary for metal thicknesses $<1 / 2$ in.

Welds between dissimilar materials, (e.g., joining stainless and low chrome steels) would probably be required in liquid metal - molten salt contactors and extractors. These are made with low chrome welding rod, also by the inert gas, shielded arc process. All these joints are stress-relieved after welding (at $705^{\circ} \pm 8^{\circ} \mathrm{C}$ for $1 \mathrm{hr}$ in the case of 347 S.S. and $2 \frac{1}{4} \mathrm{Cr}-1 \mathrm{Mo}$ steel) to eliminate the danger of subsequent cracking. If the wall thickness of the low chrome steel is $>1 / 2$ in., the joint must also be preheated to $250^{\circ}$ to $300^{\circ} \mathrm{C}$.

\section{Cleaning}

In the molten salt systems, oxide-free interior surfaces are required on all vessels and process piping, since the fused salts are subject to rapid attack by moisture and other reactive impurities. In addition, corrosion by the salts is greatly enhanced by the presence of oxidizing impurities. Three different techniques, described below, viz., electropolishing, hydrogen firing, and sandblasting, have been used successfully to clean vessels and piping prior to final assembly. Components such as valves and pressure transmitters, which require close tolerances, are assembled with initially clean parts, and the completed units are then degreased with trichlorethylene, dried, and sealed prior to installation. At the completion of fabrication, all units are maintained or shipped under an inert gas blanket.

Some of the adsorbed gases on the surfaces of the container, which would volatilize at the high operating temperatures, could react with the molten salt. To minimize this possibility, the internal surfaces of the equipment are degassed at a temperature somewhat higher than the maximum operating temperature (i.e., at $550^{\circ} \mathrm{C}$ if the latter is $500^{\circ} \mathrm{C}$ ) until a maximum system pressure of $10 \mu$ $\mathrm{Hg}$ is attained.

Electropolishing. In electropolishing, the item to be cleaned is made the anode and another piece of the same material, either larger or smaller but having approximately the same shape, is made the cathode. The electrolyte used to polish 347 S.S. contained $60 \%$ by volume of $85 \%$ reagent grade $o$-phosphoric acid and $20 \%$ by volume of $93 \%$ technical grade sulfuric acid, the balance being 


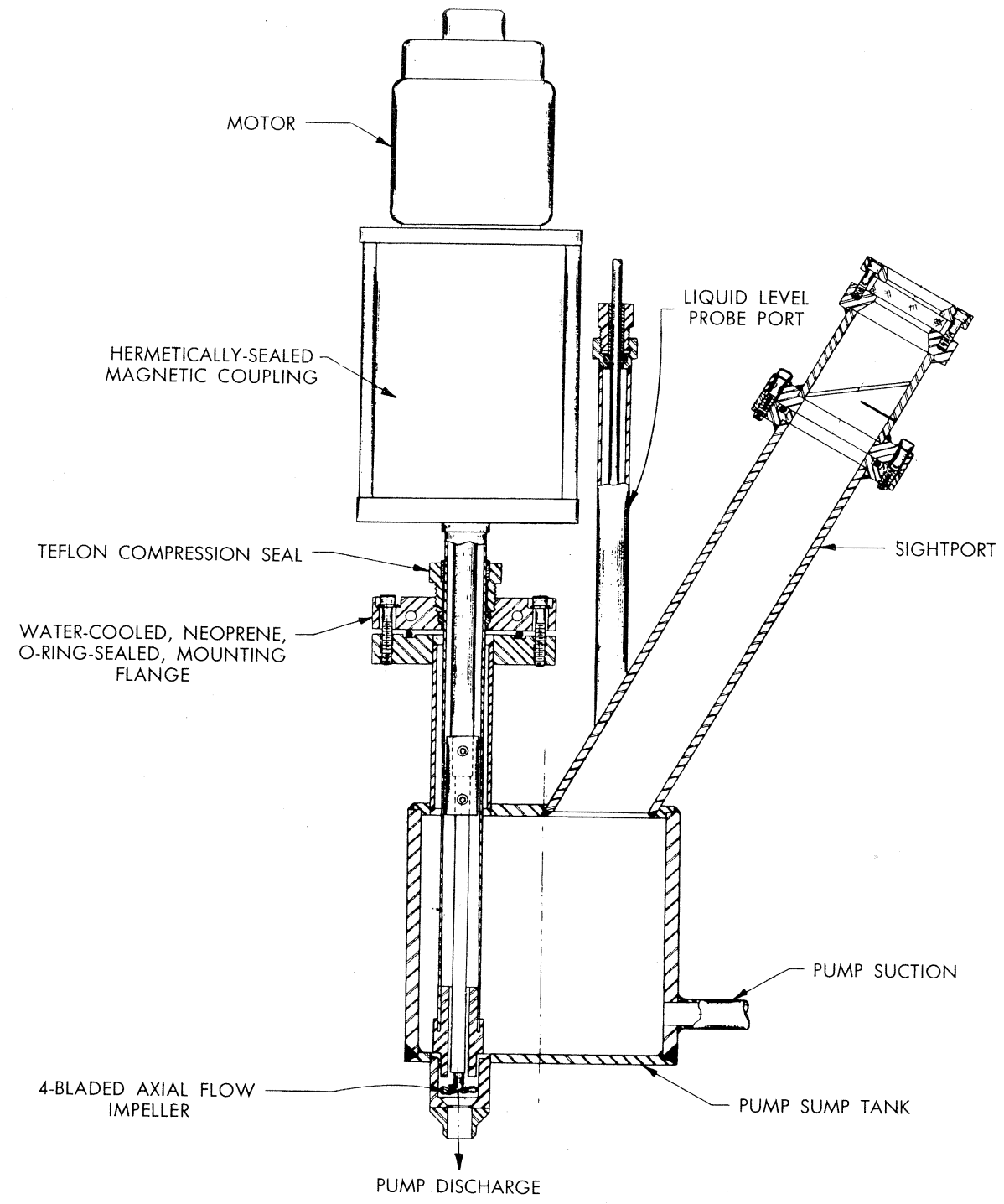

Figure 2. Axial flow salt pump with magnetically coupled, 1/12-hp, variable speed, ac-dc motor.

distilled water. Current densities of 0.3 to 5 amp/in. ${ }^{2}$ at 3 to $12 \mathrm{v}$ for periods of 5 to $30 \mathrm{~min}$ were found satisfactory. After electropolishing, the anode is washed with cold water and mechanically cleaned with a brush and hot water to remove any excess acid and oxide coating. This cleaning method is useful for small items, but does not lend itself readily to cleaning larger-scale units, besides being too costly. It was, therefore, superseded by sandblasting.

Hydrogen Firing. The purpose of hydrogen firing is to reduce oxides, primarily those of iron, present on the walls of the vessel. $\mathrm{H}_{2}$ is purified by passing it through a Deoxo unit and introduced into the vessel at room temperature. The vessel temperature is then gradually raised to $550^{\circ} \mathrm{C}$, and gas flow is continued until a dew point of $<-50^{\circ} \mathrm{C}$ is obtained. This method was found to be suitable for small systems, but the explosion hazard makes it undesirable for use in large systems.

Sandblasting. This method of cleaning was found to be the most satisfactory, being applicable to all types of container systems. The interior of each vessel is sandblasted with clean, dry, 30 to 40 -mesh sand at a pressure of 60 psig. This operation is repeated until the surface is clean and free of all rust and discoloration. It is then wirebrushed and vacuumed to remove the excess sand. 


\section{Testing}

All welds in a molten salt or liquid metal - molten salt system are examined for flaws radiographically with $\mathrm{Co}^{60}$ or $\operatorname{Ir}^{192}$ sources. The most common defects found were porosity and lack of penetration.

All vessels and loop piping sections are normally subjected to a hydrostatic (or pneumatic) test to demonstrate their structural soundness. The test pressure is $1 \frac{1}{2}$ times the design pressure at the design temperature (11/4 times in the pneumatic test) and must be maintained for $15 \mathrm{~min}$. In order to meet BNL cleanliness requirements, clean trichlorethylene, free of moisture and decomposition products, is used as the test fluid. Nitrogen is used in the pneumatic test.

During initial leak testing, large leaks are located by pressurizing the system with inert gas and applying a soap solution to all joints. Smaller leaks are detected by evacuating the system and probing the exterior of all joints with $\mathrm{He}$. A He mass spectrometer leak detector connected to the system will then indicate extremely small leaks. Leakage $>5 \times 10^{-3} \mu-\mathrm{ft}^{3} / \mathrm{hr}$ per unit tested is not tolerated in fused salt equipment.

\section{Repair Procedures}

Before repairs are made on fused salt systems, radiographic inspection of a defective component is an excellent time-saving method for locating and determining the cause of faulty operation. Radiation from isotopes such as $\mathrm{Co}^{60}$ and $\mathrm{Ir}^{192}$ has been used successfully on piping and equipment in both the presence and absence of salt. It is gen-

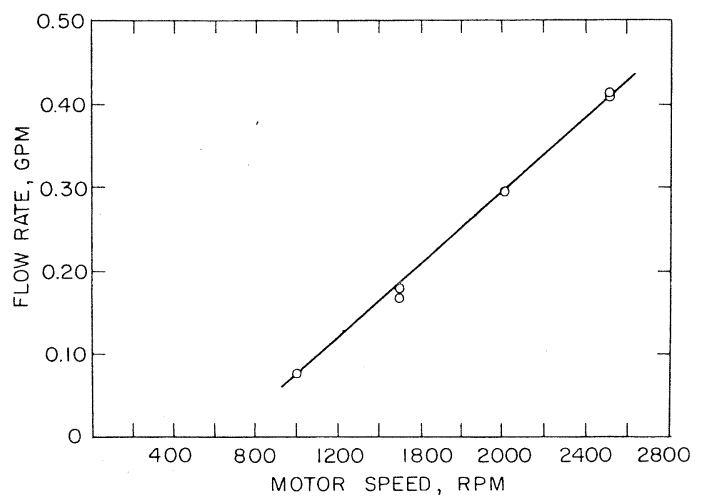

Figure 3. Calibration curve for the axial flow salt pump. (Impeller: 2 blades, $23-\mathrm{mm}$ diameter, $10^{\circ}$ pitch; motor: 1/12-hp, ac-dc; magnetic coupling: Indox I rings.) erally not necessary to remove the insulation from the equipment unless maximum definition is required, and, if a water-cooled film holder is used, the equipment may even be kept at the operating temperature.

Radiography is extremely useful for monitoring the interior of piping, pumps, and valves. Breakage, plugging, and corrosion have been observed without opening the system. When the system must be opened, however, the following techniques are recommended to minimize contamination of the system prior to rewelding:

1. If possible, the system should be drained and then cooled to room temperature.

2. Inert gas should be maintained inside the system, and, when it is opened, an outward flow of gas must be maintained.

3. All surface deposits of salt must be removed from the areas to be welded. Removal of part of the inner wall by reaming has been found necessary to insure complete salt removal. The pipe should be cooled at the point where the reaming stopped to prevent salt from melting and running into the weld zone during welding.

Salt may be removed from the surface of vessels by rinsing with hot water, but care must be taken to dry the vessel completely afterwards, since any moisture will react with the eutectic to cause severe corrosion of the container. The vessel should then be sandblasted and prepared for service again as described above.

\section{MECHANICAL COMPONENTS}

\section{Pumps}

The ternary eutectic has been circulated successfully at $500^{\circ} \mathrm{C}$ with several different centrifugal pumps at flow rates up to $12.5 \mathrm{gpm}$ and with heads up to $46 \mathrm{ft}$. Each pump was totally canned and mounted vertically with an overhung shaft and impeller. No attempt was made to run with bearings in the salt-filled sump. As a result, relatively low efficiencies of 1 to $10 \%$ were obtained.

A small, magnetically coupled, axial flow pump (Figure 2) was developed for use in small-scale dynamic corrosion loops. A 1/12-hp motor and magnetic coupling. with Indox I ceramic ring magnets were used to obtain flow rates of $3.2 \mathrm{gpm}$ against a head of $0.5 \mathrm{ft}$ in a 1000 -hr test. The pump was equipped with a two-bladed impeller, $23 \mathrm{~mm}$ in diameter and pitched $10^{\circ}$ from the vertical. Prior to use, the pump was calibrated with water 


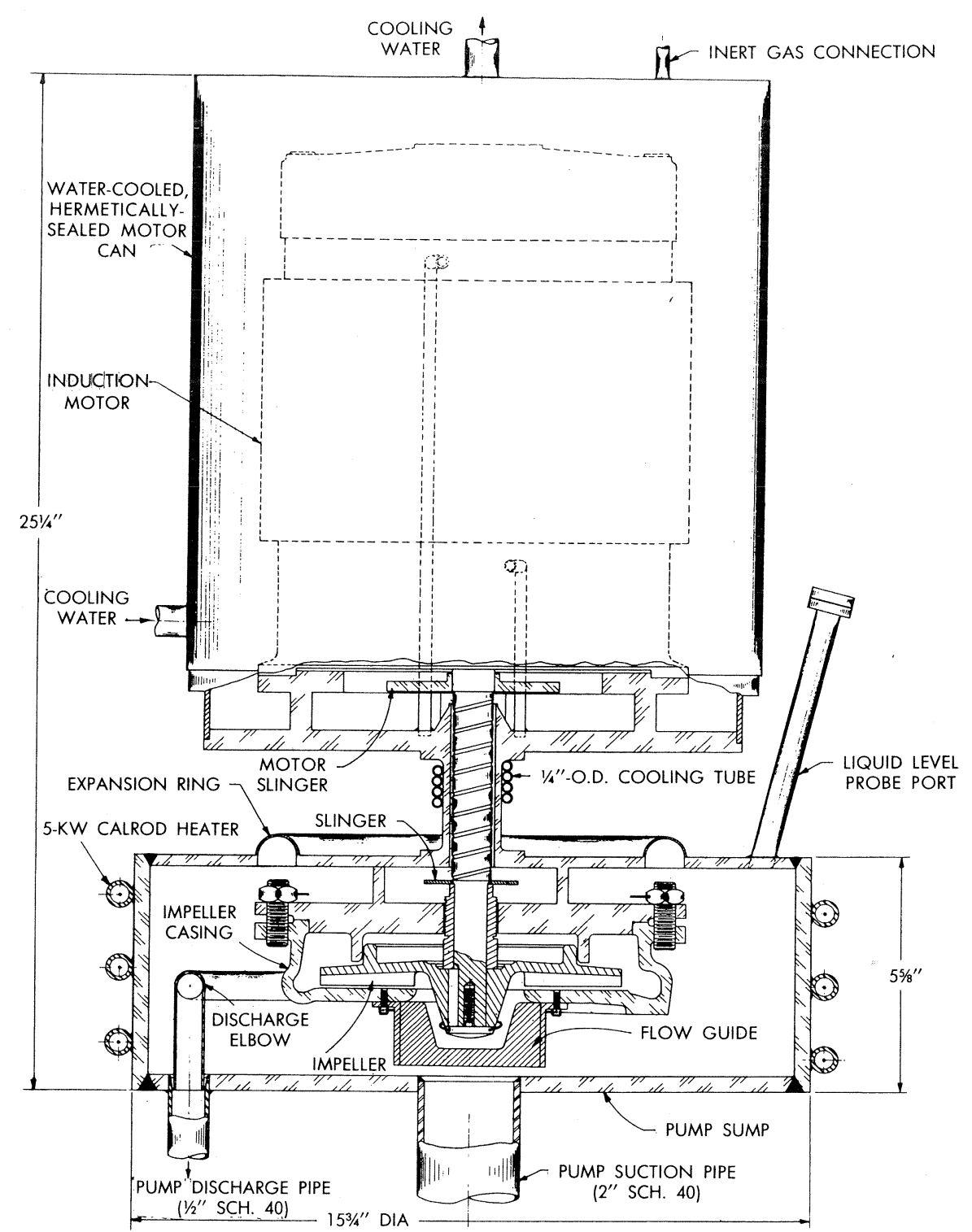

Figure 4. Canned-motor, fused salt centrifugal pump, 11/2-hp (All parts in contact with salt are type 316 or 347 S.S.)
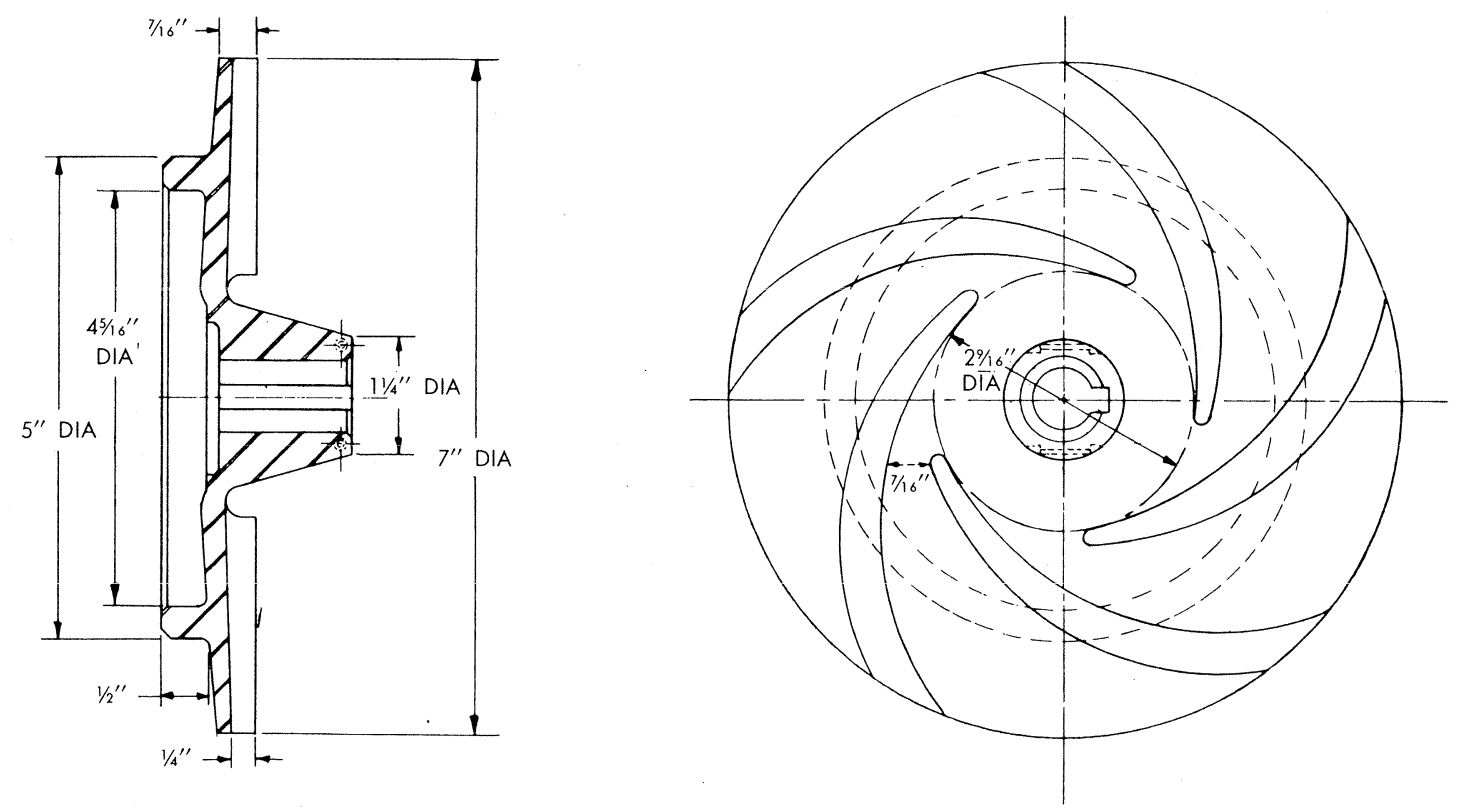

Figure 5. Impeller for the 1/1/2-hp, canned-motor, fused salt centrifugal pump. 


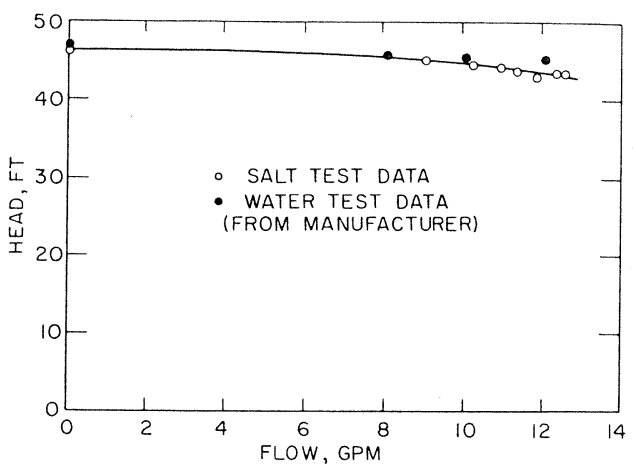

Figure 6. Calibration curve for the 1/1/2-hp, canned-motor, fused salt centrifugal pump. (Impeller: 7 -in. diameter, five $1 / 4$-in.-high blades; operating $T=520^{\circ} \mathrm{C}$.)

as the test fluid in an exact replica of the loop in which it was to be placed. ${ }^{8}$ The calibration curve is shown in Figure 3.

Three other pumps have been tested at Brookhaven for use in larger salt loops.

A canned-motor centrifugal pump (Figure 4) built by the General Electric Company and rated for $11 \mathrm{gpm}$ at a $45-\mathrm{ft}$ head operated satisfactorily. The parts in contact with the fused salt were made of 347 and 316 S.S. The pump consisted of two cans, the water-cooled motor enclosure and the Calrod-heated pump sump, interconnected with a water-cooled tube surrounding the impeller shaft whose purpose was to prevent heat conduction from the salt to the motor. A 7-in.-diameter, 5bladed impeller (Figure 5) and volute were used. The 11/2-hp, 1500-rpm, 3-phase induction motor ran in an atmosphere of He.

The pump was operated for $1034 \mathrm{hr}$ with salt at $520^{\circ} \mathrm{C}$ and produced a head of $44.5 \mathrm{ft}$ at a flow of $11 \mathrm{gpm} .{ }^{9}$ In Figure 6 the calibration curve obtained for salt service is compared with the water test data supplied by the manufacturer. The salt data fell slightly below those for water at the higher flow rates. A maximum flow of $12.5 \mathrm{gpm}$ was obtained.

Although the unit met flow rate and head specifications, the design would have to be revised to make long-term operation possible. The primary source of operating difficulty was the formation of salt plugs in the gas space above the salt surface, probably caused by splashing. One such plug occurred in the collar between the pump and motor cans. This did not prevent pump operation, i.e., the pump shaft did not seize, but, since the blanket gas was originally introduced to the motor can above this collar, the plug caused a pressure unbalance between the pump can and the surge tank which resulted in the pump being tripped out by both high and low liquid level alarms. Heating of the collar proved to be only a temporary remedy. An auxiliary gas line was finally installed in one of the pump liquid level probe housings below the collar, and pump operation continued. Further salt deposition occurred at the liquid level probes, however, eventually shortcircuiting them. Time did not permit modification of the probe housing before the test was terminated.

A canned centrifugal pump (Figure 7) was developed at Brookhaven with a commercially available pump (Ruthman Machinery Co. Gusher pump) as the basic element. A 4-in.-diameter impeller with 8 blades, 3/4 in. high, inside a volute was used (Figure 8). It was overhung from the sealing flange mounted on the top of the 12-in. and 16-in.-IPS sump. The bottom of the sump was heated with resistance heater wire, and its upper end was water-cooled. A hermetically sealed magnetic coupling (Figure 9) was developed and tested at Brookhaven for use in conjuction with the 3-hp, dc, variable speed, 1750-rpm motor to drive this pump. ${ }^{10}$ In this case the motor was mounted outside the hermetically sealed salt system. A water flow of $0.5 \mathrm{gpm}$ was maintained in the cooling jacket surrounding the sealing can in the magnetic coupling to remove the eddy current heat generated within the steel can by the rotating magnets.

The pump sump was provided with a series of baffles around the shaft to prevent salt from reaching the cooler regions of the pump. Little evidence of splashing was found at the end of the pump tests. Salt liquid levels were measured with resistance-type probes mounted in a side arm connected to the sump. No unusual operational difficulties were encountered with this arrangement. The pump was operated continuously in salt at $515^{\circ} \mathrm{C}$ at speeds of 750 to $1900 \mathrm{rpm}$ for $512 \mathrm{hr}^{9}$ Pump characteristics for the unit are given in Figure 10. Flow rates up to $7 \mathrm{gpm}$ and heads up to 17 $\mathrm{ft}$ were obtained while the salt level in the sump was varied between $71 / 2$ and 15 in.

A canned-rotor pump (Figure 11) rated for 9 gpm at a 45 -ft head was found unsatisfactory for salt service. Although the hydrodynamic bearing, absence of a gas space, and the canned rotor were features that were basically sound and desirable, 


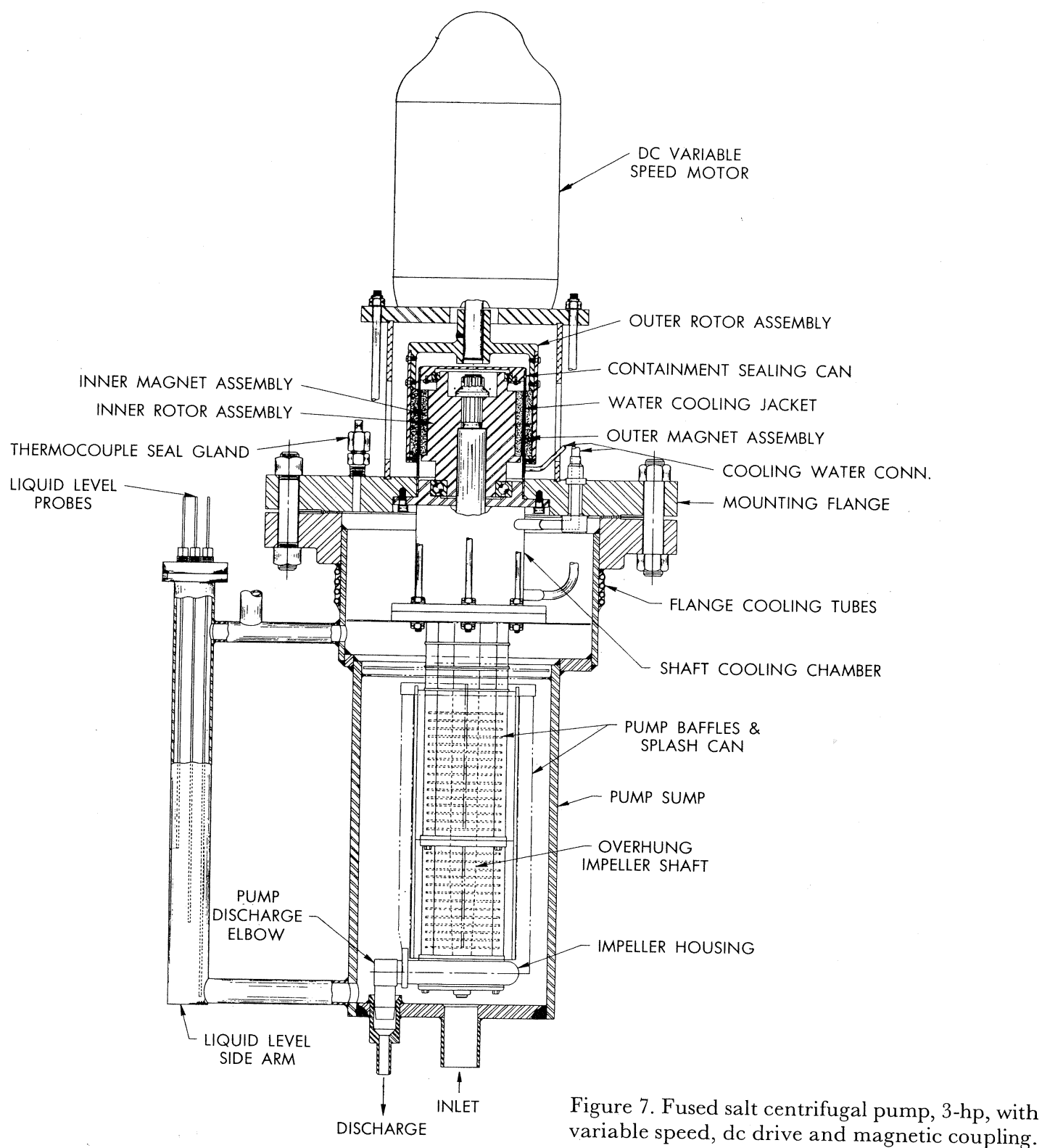

this particular design required temperature differences in the vicinity of the pump stator that were impossible to obtain during operation. ${ }^{11}$

\section{Valves}

The Crane Company metallic, bellows-sealed, Y-pattern, 1/2-in.-IPS, 300-lb globe valves (Figure 12) have been used extensively for salt service. They are leak-tight against $\mathrm{He}$ and suitable for service at $500^{\circ} \mathrm{C}$. All valve parts in contact with salt are made of $347 \mathrm{~S}$.S. The Y-pattern valves are preferred for easier and more complete drainage of the fused salt. They are designed for open or closed service.

Extra care must be exercised in selecting a valve to be used in tight shutoff service for salt. Seat leakage is a very serious problem because of the possibility of pressure surges and liquid level changes, and it appears that each valve should be mass spectrometer leak-tight across the seat before it can be used. ${ }^{9}$

For salt service in which precise throttling is required, $1 / 8$-in.-IPS commercial needle valves have been used, but with generally unsatisfactory re- 


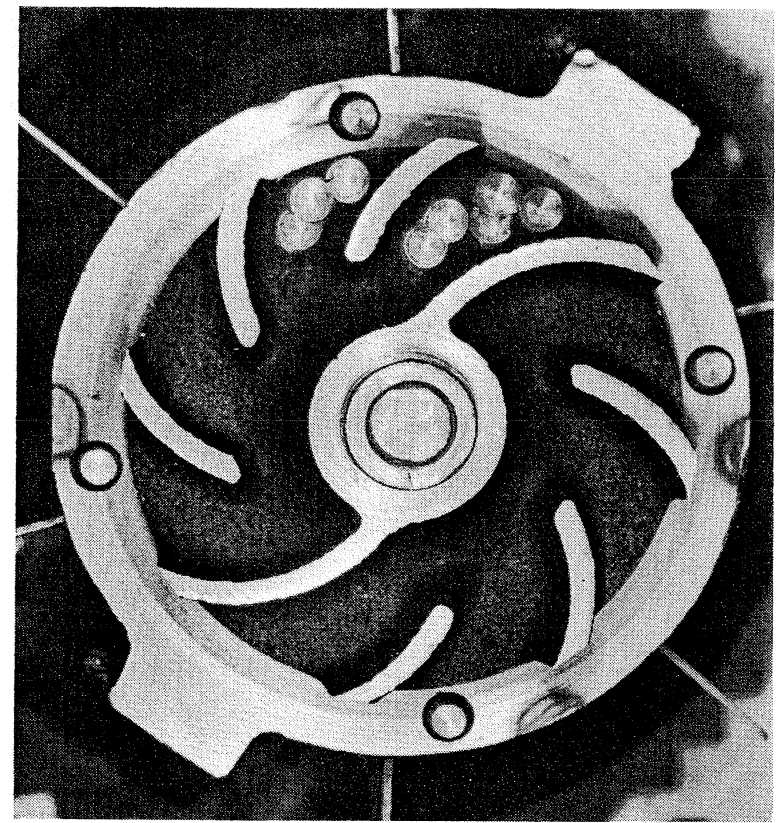

Figure 8. Impeller for the 3-hp, variable speed, fused salt centrifugal pump.

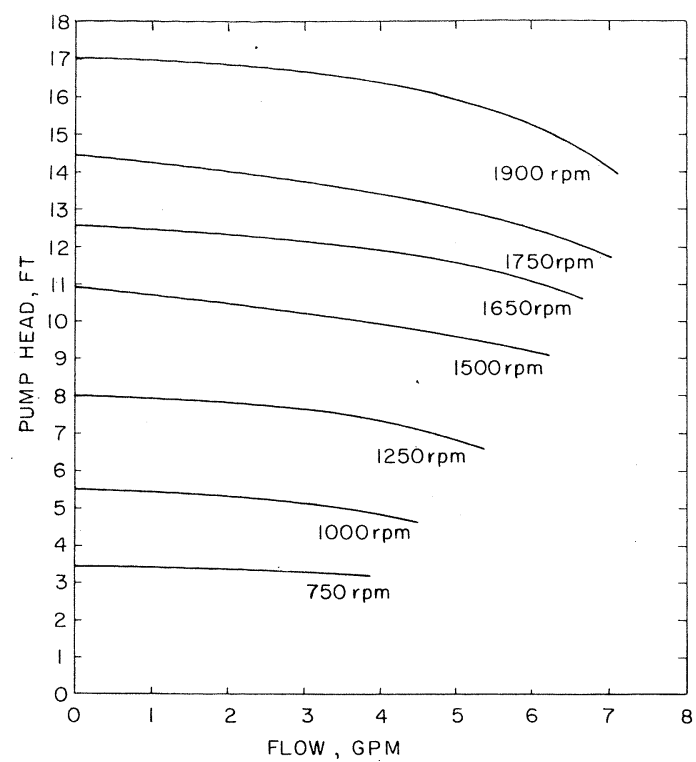

Figure 10. Calibration curve for the 3-hp, variable speed, fused salt centrifugal pump. (Impeller: 4-in. diameter, eight $3 / 4$-in.-high blades; salt $T=515^{\circ} \mathrm{C} ; P$ above salt $=15$ psig; liquid level varied between $71 / 2$ and 15 in.)

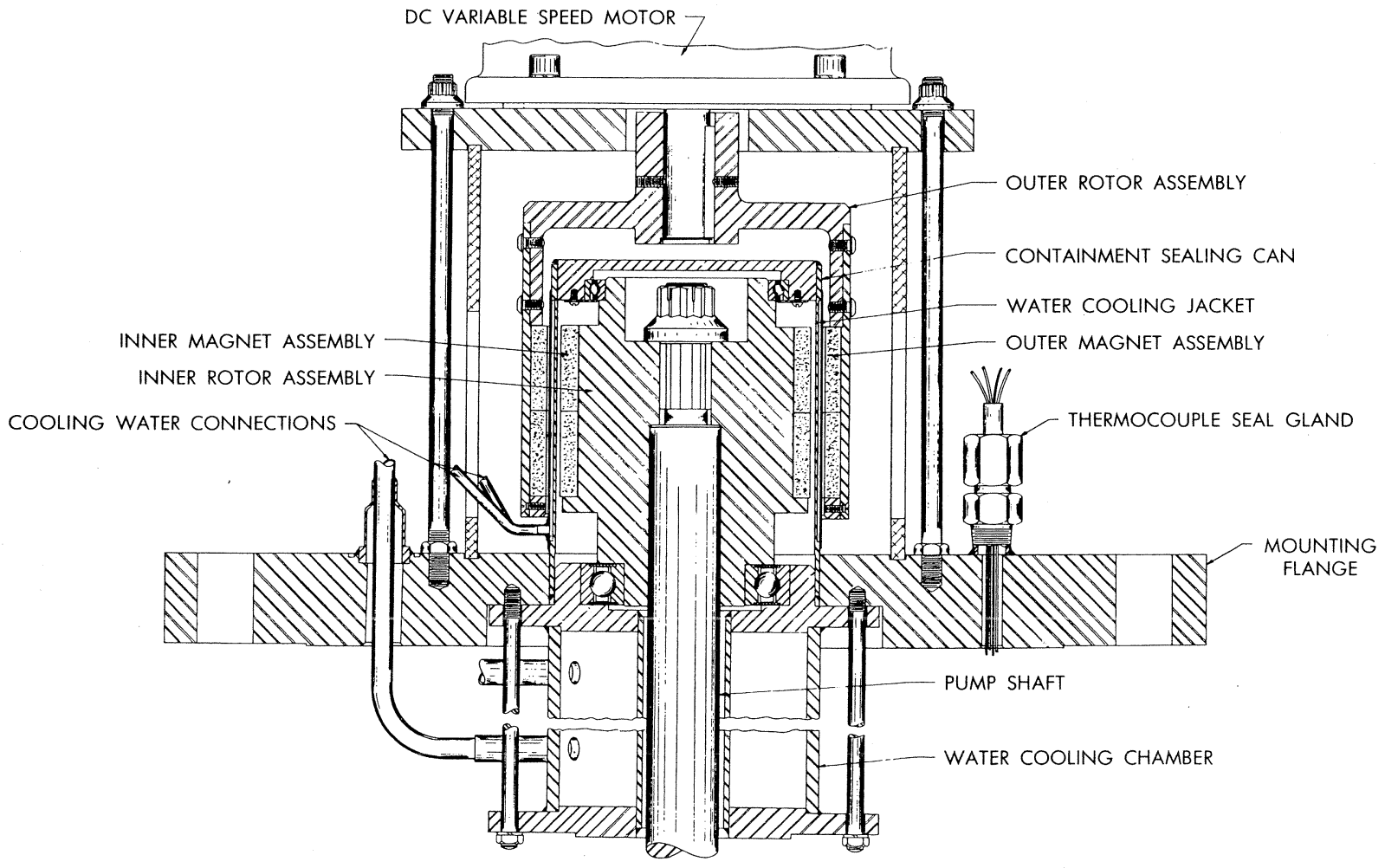

Figure 9. Magnetic coupling for the 3-hp, variable speed, fused salt centrifugal pump. 


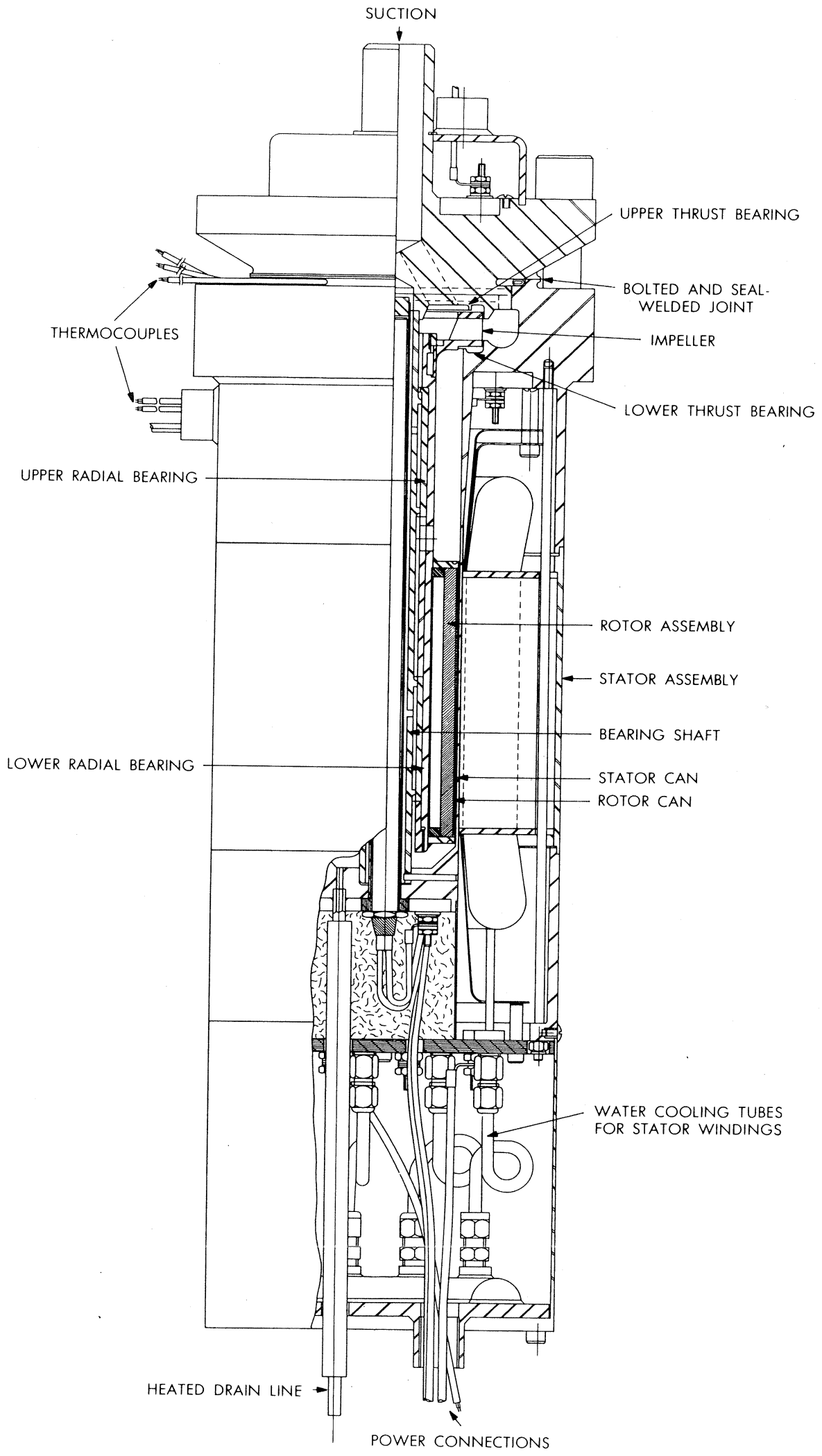

Figure 11. Canned-rotor, fused salt centrifugal pump, 3-hp. 


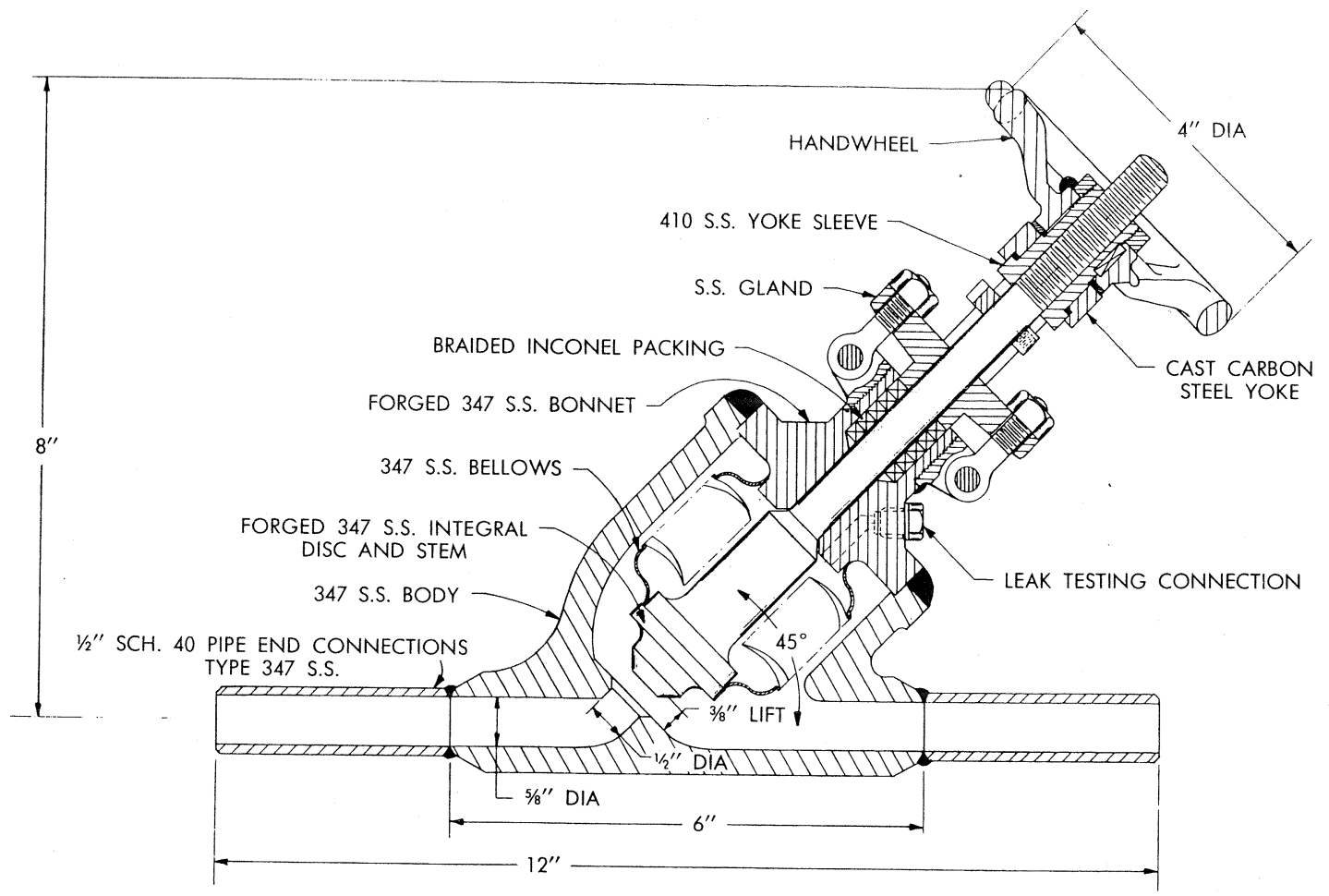

Figure 12. Typical 1/2-in.-IPS, 300-lb, Y-pattern globe valve for fused salt service.

Figure 13. Fused salt flow regulating valve, 1/2-in.-IPS.
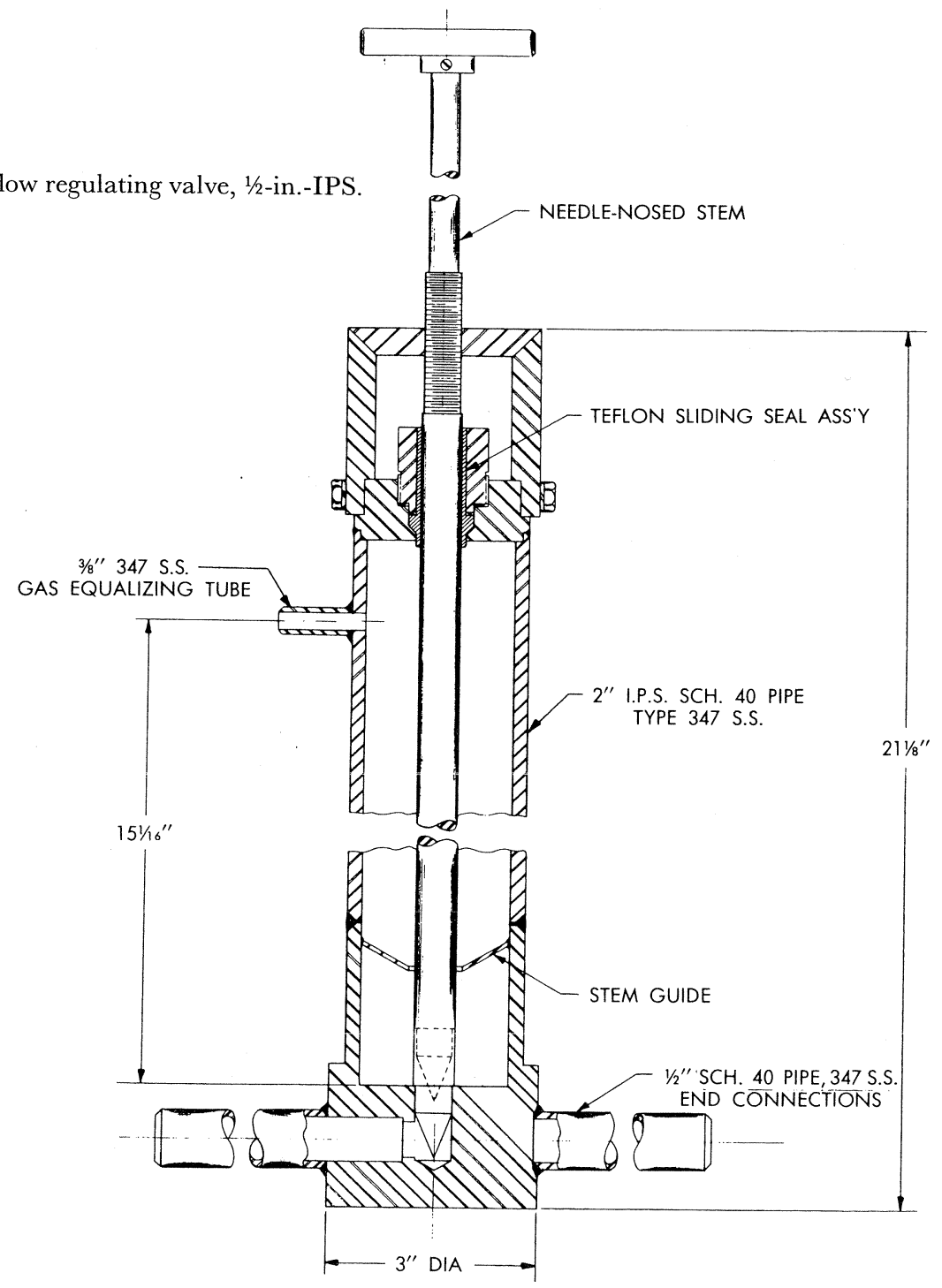


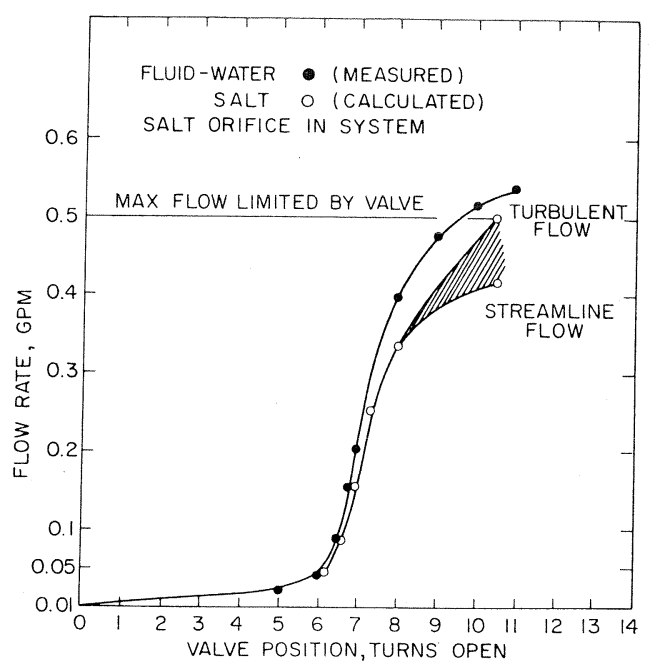

Figure 14. Calibration curve for the $1 / 2$-in.-IPS, fused salt flow regulating valve.

sults. The "as received" valves had a port size of $1 / 16$ in. which was soon found to plug with particulate matter present in the salt. Increasing the port size to $3 / 16$ in. lessened, but did not eliminate, the difficulty.

Since no satisfactory throttling valve was available for use in liquid metal - molten salt extraction systems, a needle valve was developed at Brookhaven. The valve consists of a needle-pointed calibrated stem which moves through a Wilsontype compression seal into the valve seat (Figure 13). The port size is $1 / 2 \mathrm{in}$. The valve does not have a bellows seal, which limits its use to applications of low flow rate and head. In such a system the valve must be mounted on a horizontal line near a surge or constant head tank so that the salt level in the valve housing can be maintained by means of a gas equalizing line. The valve, although limited in application, has the advantage of very fine throttling characteristics with a pressure drop of $7 \mathrm{in}$. of salt at $0.50 \mathrm{gpm}$. The valve has been calibrated with water (Figure 14) but has not been used in salt service.

Cold plugs were often used in place of valves when transferring salt from a melt or pretreatment tank to a loading tube. The $5 / 8$-in.-diameter stainless steel transfer tube would be crimped shut with a pair of bolt cutters after the operation was completed, and any salt left in the line was allowed to freeze. The line was then cut off with the bolt cutters and a final seal made with Apiezon sealing wax. The vessel could then be evacuated or pressurized without danger of gas leakage.

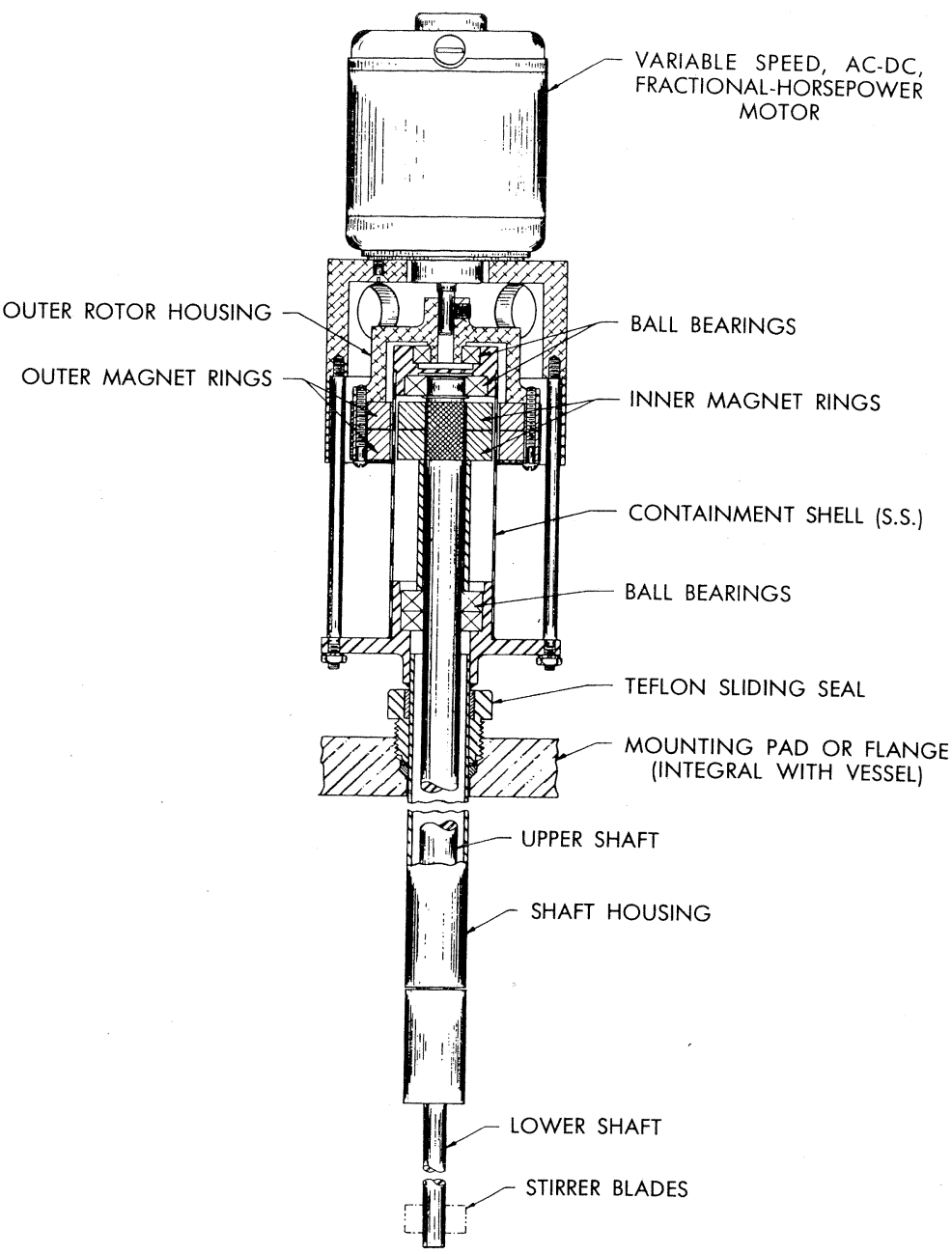

Figure 15. Magnetically coupled agitator with fractional-hp, ac-dc, variable speed drive.

\section{Flanges}

Although all-welded joints are preferred, $1 / 2$-in.IPS, 347 S.S. flanges have been used successfully in fused salt service, principally in connecting vessels for salt transfer and in orifice flowmeters. These are standard ring-type joint flanges having 347 S.S. rings with an oval cross section. With care, they can be made tight against He leakage, but particular attention must be given to the surfaces of the ring and its mating grooves to see that they are perfectly smooth and free of score marks and other slight imperfections. The joints must be checked again at elevated temperatures to be certain that the bolt tension has not decreased.

Flanges in the gas phase are usually cooled with water coils or air blowers to permit the use of 


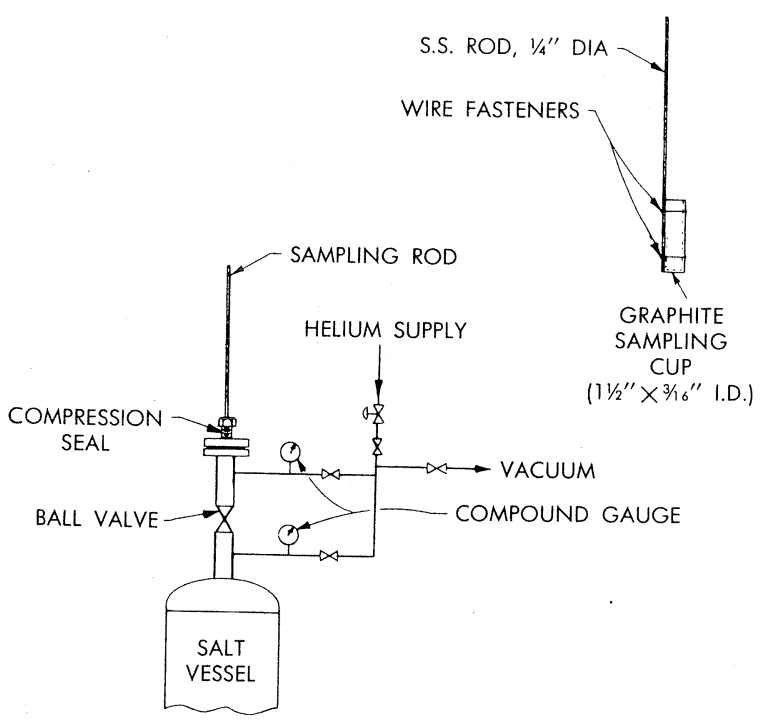

Figure 16. Thief-type salt sampler.

standard O-ring or gasket materials such as Neoprene or Teflon.

\section{Agitators}

Certain experiments, such as liquid metal molten salt equilibration studies or the dissolution of tracers, require the use of agitators. A propellertype stirrer with a magnetic coupling to seal the system against gas leakage, similar to the axial flow pump previously described, has been developed at Brookhaven ${ }^{10}$ (Figure 15). These units are usually powered with $1 / 4-h$, variable speed, ac-dc motors. Each has two $1 / 2 \times 1$-in. blades with a maximum tip speed of $520 \mathrm{ft} / \mathrm{min}$. For equilibration studies, agitators were equipped with two sets of blades so that the two phases could be stirred simultaneously.

In applications in which salt could not be mixed with the rotary magnetic stirrers because the required shaft length was too great or the vessel diameter too small, a vibrator was used. The vibrating stirrer consisted of a light-weight shaft (usually tubing) to which a thin plate was attached at the lower end. This end was then submerged in the fluid to be agitated. The top of the shaft was attached to an armature which vibrated in an ac field, the amplitude being controlled by varying the voltage. The armature assembly was canned, and the shaft housing was attached to the vessel through a Wilson-type compression seal. The vibrating stirrer has the advantage that it does not require high speed rotating parts, careful alignment of parts, or accurate machine work, since bearings are not used.

\section{Sightports}

Sightports are used for observing the inside surfaces of the experimental vessels and also the free salt surfaces during operation. Each sightport is permanently welded into the vessel, either in the form of a rigid length of pipe, or as a steel bellows for greater flexibility in viewing the vessel interior. A Pyrex sight glass mounted on a Neoprene Oring hermetically seals the unit. A flapper valve to protect the sight glass against salt deposition is mounted either in-line with the port or eccentrically in a specially enlarged section for an unobstructed view and is operated by turning an externally attached magnet.

\section{Samplers}

It is often essential that molten salt systems be sampled to determine the concentration of corrosion and fission products and U. For normal applications, a simple thief-type sampler (Figure 16) has been developed. All samples are taken in 3/16in.-i.d. $\times 1 \frac{1}{2}$-in.-long AGOT graphite cups that have been outgassed at $800^{\circ} \mathrm{C}$ at a pressure of 1 $\mu \mathrm{Hg}$. The graphite sampling cup is attached to a clean steel rod and introduced into an air lock through a Teflon sliding seal. The air lock is isolated from the salt system with a Jamesbury Neoprene-sealed ball valve. Air is removed from the sample container and air lock by alternately evacuating and purging the chamber with $\mathrm{He}$. The He pressures in the air lock and in the main system are then equalized, and the ball valve is opened. The sampling rod is pushed through the seal into a position such that the graphite cup is in the heated portion of the vessel and above the level of the molten salt. After sufficient time has been allowed for the cup to reach the temperature of the salt ( $5 \mathrm{~min}$ ), it is lowered into the salt and filled. The sample rod and cup are then withdrawn to a position in the cold zone immediately below the ball valve, where the salt solidifies. The sample is then raised through the ball valve. The ball valve is closed and the salt sample withdrawn from the air lock. This type of sampler has been in continuous service for several years. Although sampling by this method is simple and reliable, it is very time consuming; therefore an in-line sampler has been developed and tested for use in mass 


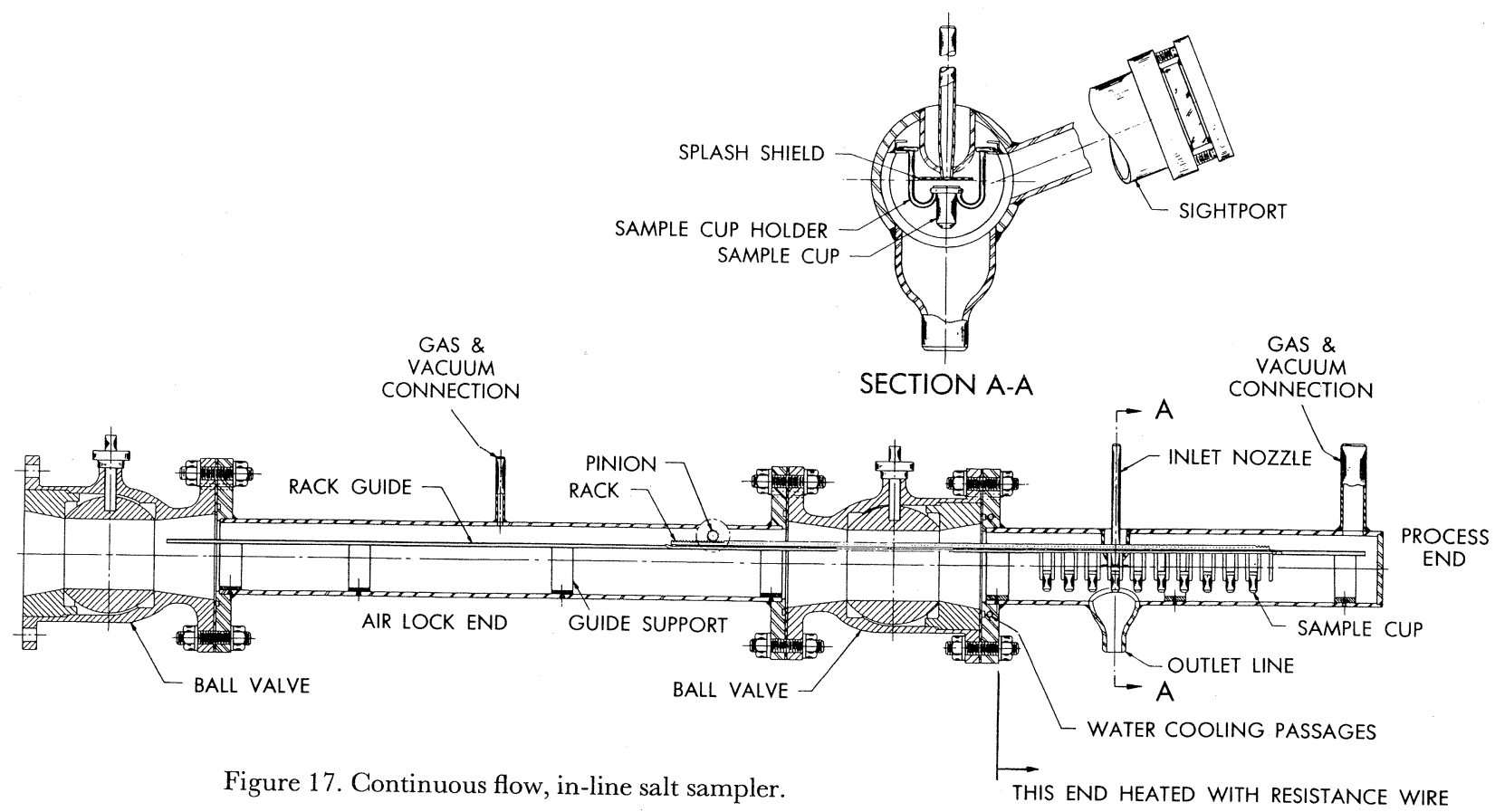

transfer experiments in liquid metal - molten salt systems.

The in-line sampler (Figure 17) permits as many as 10 consecutive samples to be taken only seconds apart from a continuously flowing stream of fused salt. ${ }^{12,13}$ The samples are taken in $3 / 8$ in.-diameter $\times 3 / 4$-in.-long steel or graphite cups mounted on a sample cup holder (Figure 18) which is driven by a rack-and-pinion mechanism through a small stream of salt. The pinion is rotated manually from the outside through a Teflon sliding seal. The salt end of the sampler is electrically heated to maintain the flowing salt and the sample cups at the system operating temperature. The cup holder is projected into the heated chamber through a 4-in.-diameter Neoprene-sealed ball valve in such a manner that as samples are taken the holder is progressively withdrawn into the air lock, and when the ball valve is finally closed, the 10 fresh samples are isolated from the flowing salt. A notch-and-spring catch mechanism positions the cup holder in such a way that the inlet nozzle is either directly over a cup when sampling, or between two cups at other times, the salt exiting through the outlet line. The sample cups are removed by opening another 4 -in.-diameter ball valve and withdrawing the holder from the air lock. Appropriate vacuum and $\mathrm{He}$ connections are provided for purging the air lock and equalizing pressures in both chambers before the main ball valve is opened. A sightport is located at the salt end of the sampler for observing the filling of the sample cups.

\section{Filters}

As a protection against foreign matter and insoluble impurities, the molten salt from the melt tank is filtered before being charged into the pretreatment tank. The filter consists of a $1 / 8$-in. plate of sintered 347 S.S. with a mean pore size of 20 or $35 \mu$ which is welded inside pipe fittings to form an enlargement in the pipe line mounted in such a position that it will drain back to the melt tank.

\section{INERT GAS SYSTEM}

The surface of the salt is always blanketed with a purified inert gas, either $\mathrm{He}$ or Ar, to prevent contact with air or moisture. The equipment for the purification and distribution of this gas and a vacuum system make up the inert gas system.

Cylinder He is purified to remove traces of moisture and $\mathrm{O}_{2}$ by passing through a standard refrigeration-type silica gel dryer and through tubes of Ti chips held at $900^{\circ} \mathrm{C}$. The purity of the effluent gas is checked by passing it over a highly polished piece of $\mathrm{U}$ at $900^{\circ} \mathrm{C}$, any dulling indicating impurities. A Minoxo Indicator, manufactured by 


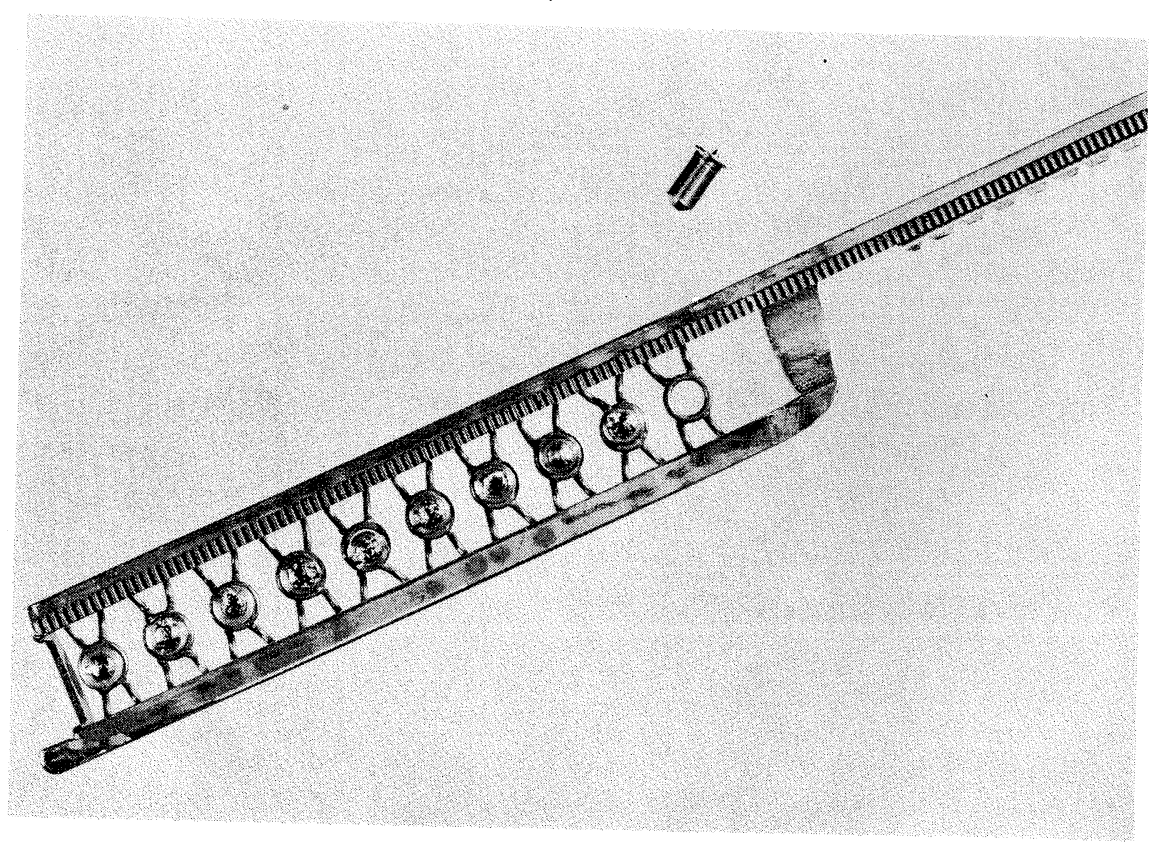

Figure 18. Sample cup holder carriage for in-line salt sampler.

Baker and Company, was briefly used to monitor and record continuously the $\mathrm{O}_{2}$ concentration in the purified He. Its operation is based on a galvanic cell with a $\mathrm{Ag}$ cathode and a Cd anode separated by a tube of saturated $\mathrm{KOH}$, the millivolt output from the cell being proportional to the $\mathrm{O}_{2}$ concentration in the gas, which can be as low as $0.5 \mathrm{ppm}$. He containing $<5 \mathrm{ppm}_{2}$ was used. Lamp grade Ar is used without further purification.

The vacuum system consists of conventional high vacuum equipment and instrumentation and is used to purge samplers and other parts of a salt system that may become contaminated with air. An oil-sealed mechanical vacuum pump with a shutoff pressure up to $20 \mu \mathrm{Hg}$ is adequate for this service. Another function of the vacuum system is to provide a vent header for $\mathrm{He}$ exhaust, since venting of exhaust He to a vacuum header eliminates contamination of the inert gas system by back diffusion of air. The vacuum system must also maintain the salt system at a low pressure (1 to $10 \mu \mathrm{Hg}$ ) during the degassing operation. An oil diffusion pump is used for this operation. A special high speed vacuum system, used in the preparation of the fused salt, is described later in connection with salt preparation.

All vessels in the piping system are fitted with a gas and vacuum connection. All gas and vacuum piping and fittings must be tight to a $\mathrm{He}$ mass spectrometer leak test; therefore, the joints are silver-soldered. Before installation, all valves, pressure regulators, and other components are disassembled, carefully cleaned and degreased, and inspected for imperfections.

\section{INSTRUMENTATION}

\section{Liquid Level Indicators}

Since there are usually several free surfaces in a molten salt system, a reliable liquid level indicator is required. Stationary metallic probes with their ends at different salt levels, which complete an electrical circuit when the molten salt touches them, have been used extensively. They have proved reliable so long as the salt surface remained quiescent and no salt splashed and deposited on the probe housing to short-circuit them, as was the case in one of the centrifugal pump sumps. This difficulty was successfully overcome by locating the probes in a side arm attached to the sump. An adjustable probe has been made by inserting the probe through a Teflon sliding seal. It can be used to follow a changing salt level with an accuracy of $\pm 1 / 8$ in. Extreme care must be taken when following a changing liquid level with a movable probe because a reduction in the pressure differential of 


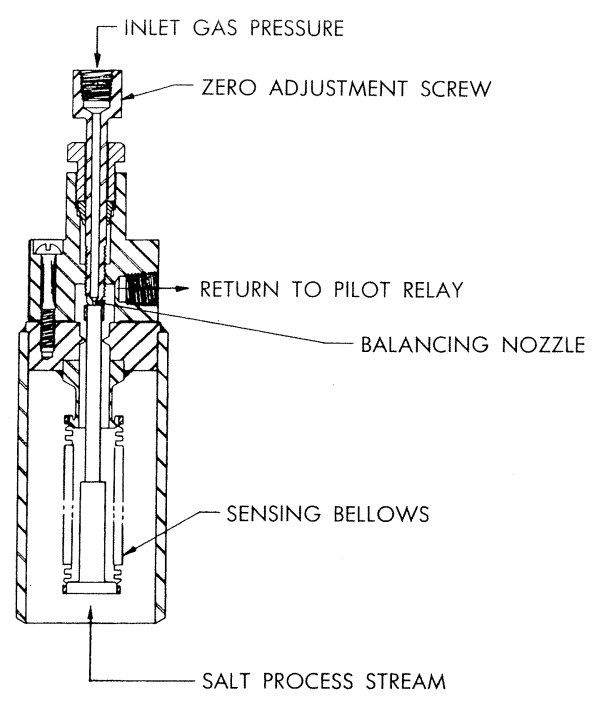

Figure 19. Nullmatic, pilot operated, fused salt pressure transmitter.

1 psi (which might occur in case of seal leakage) will result in a rise in salt level of $15 \mathrm{in}$.

A stainless steel float was used to measure the salt level in a completely welded vessel in which compression seals or other nonwelded joints were not permitted. ${ }^{14}$ On the float was mounted a length of steel rod which projected into a sealed steel tube welded to the top of the vessel. The position of the rod was determined with a high temperature induction search coil mounted externally to the tube in which the rod moved.

A thermocouple-type liquid level indicator was installed in a similar all-welded vessel, but it did not operate successfully. ${ }^{15}$ It consisted of a series of Chromel-Alumel thermocouples welded to the walls of a thermocouple well in which cooling air was circulated. In principle, a change in the temperature gradient should be observed at the height of the salt - blanket gas interface.

\section{Pressure Transmitters}

The only pressure transmitter used for continuous fused salt service at Brookhaven was the Moore Products Co. 316 S.S., nullmatic, pilot operated unit (Figure 19). It proved very satisfactory, and it can be made very sensitive and rapid in response. A thin $316 \mathrm{~S}$.S. metallic bellows seals the unit and also serves as the sensing element. The full-range bellows movement is only a few thousandths of an inch. The backing gas is $\mathrm{N}_{2}$, and the sensing system is adjusted to maintain a maximum differential across the bellows of 10 psi.

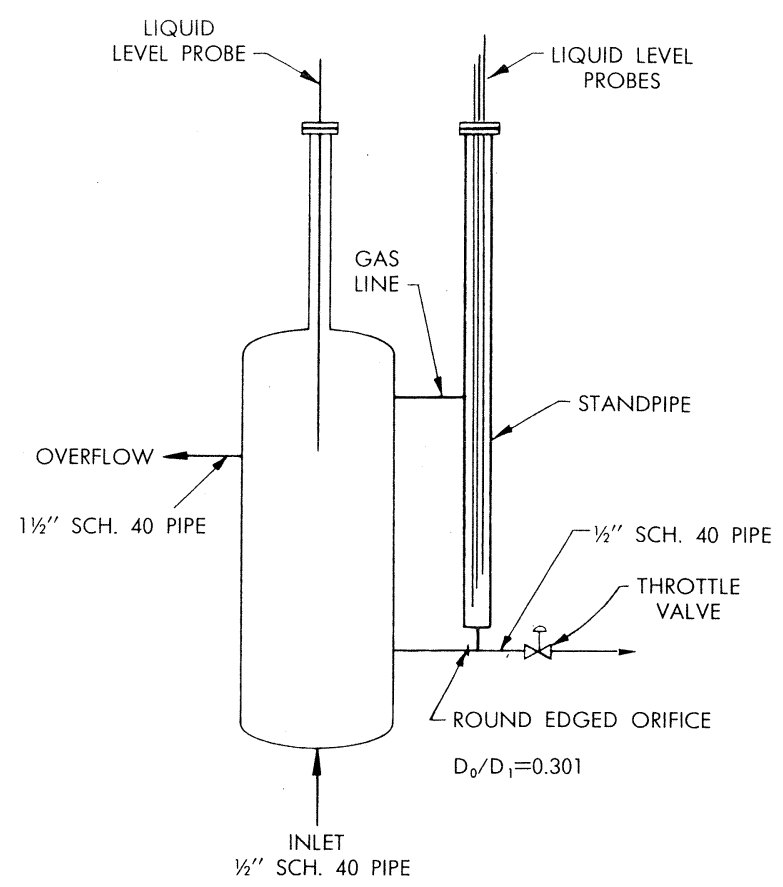

Figure 20. Low salt flow, orifice flowmeter installation.

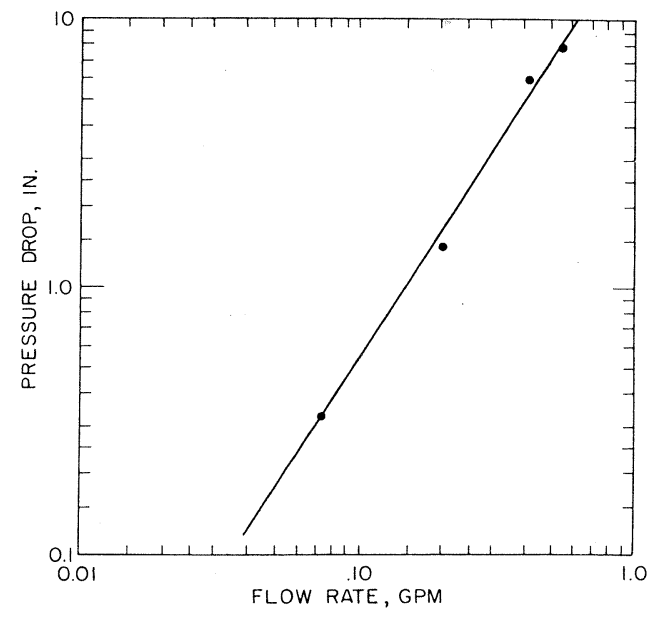

Figure 21. Low salt flow, orifice flowmeter calibration curve. (Orifice i.d. $=0.1875$ in.; pipe i.d. $=0.622$ in.)

The main disadvantage of the unit is the large $\mathrm{N}_{2}$ consumption, approximately one $220-\mathrm{ft}^{3}$ cylinder per day per transmitter.

\section{Flowmeters}

Rounded-edge orifice and Venturi flowmeters made from 347 S.S. have been used for salt service at flow rates of 2 to $12 \mathrm{gpm}$ in $1 / 2$-in.-IPS lines. The $1 / 8$-in.-thick orifice plates were machined with in- 
tegral metallic rings to be used with $1 / 2$-in.-IPS ring-type joint flanges and flange pressure taps. The Venturi measurements showed somewhat less scatter than those obtained with the orifice.

For use in liquid metal - molten salt systems, the following method was devised to measure salt flow in the range of 0.15 to $0.50 \mathrm{gpm} .{ }^{16} \mathrm{~A}$ roundededge orifice was mounted on a $1 / 2$-in. pipe between a constant head tank and a standpipe interconnected with a gas pressure equalizing line (Figure $20)$. Before the salt starts to flow, the salt level in each vessel is equal. As flow is established, the salt level in the standpipe drops. This change in liquid level between the constant head tank and the standpipe is measured and is a function of the flow rate. This unit has been calibrated with water (Figure 21) but has not been used in salt service.

\section{Temperature Measurement}

Chromel-Alumel thermocouples are either welded to the outside of the piping and other equipment or inserted into thermocouple wells. Care should be taken to ensure that all potential static legs of salt in the system are given adequate thermocouple coverage. Conventional indicating, recording, and controlling instruments are connected to the couples. ${ }^{14,15}$

\section{SALT PREPARATION AND HANDLING}

\section{Preparation of Salts}

The fused binary and ternary eutectics were very carefully prepared by the procedures described below to produce pound quantities of a crystal-clear, colorless liquid. Although these procedures are similar to the mehtods for gram-scale preparation described by Bareis ${ }^{1}$ and by Raseman et al. ${ }^{17}$ for preparing the binary eltectic, they differ considerably from those of Ginell ${ }^{18}$ for the ternary eutectic. In both cases, however, the most stringent requirements of cleanliness and leak tightness were observed. In the large-scale preparation of the ternary salt it was not practical to purify the individual reagents before use by such methods as recrystallization and sublimation. Instead, the "as received" materials from freshly opened packages were used. The $\mathrm{MgCl}_{2}$, which contained relatively large quantities of moisture, was dehydrated by slow heating at very low pressures, but in the absence of a stream of dry hydrogen chloride. The use of such relatively large quantities of reagents also produced significant amounts of insoluble im- purities. These were allowed to settle to the bottom of the melt tank so that they would not be transferred through the dip tube transfer line which terminated about 4-in. above the bottom. Nonsettled insolubles were removed by a filter in the discharge line. Since the salt was used primarily in experiments involving liquid metal - fused salt equilibrations and fused salt corrosion studies, the utmost degree of purity, especially the absence of oxidizing substances, was required. This condition was approached on the large scale by pretreating the fused salt with a reducing solution of $\mathrm{Bi}-\mathrm{U}$ $\mathrm{Mg}$. The optimum conditions for this pretreatment, however, were not determined, nor was any other method of preparation and purification studied. A description of the equipment and the procedures for preparing the salts follows.

Melt Tanks. The LiCl-KCl eutectic was prepared in a portable 347 S.S. tank, made from 8-in. pipe, having an over-all height of $36 \mathrm{in}$. and a salt capacity of $0.87 \mathrm{ft}^{3}$ (Figure 22). The bottom was sealed with a weld cap and the top with a ringtype joint flange with a metallic ring. The salt was discharged through a $1 / 2$-in.-IPS dip tube with a partially shielded, 20- $\mu$, sintered 347 S.S., bayonet filter (Micro Metallic Corp.) at one end, and a flexible 347 S.S. tube with a Y-pattern globe valve and flange at the other. A 1-in.-IPS flanged charge connection, two resistance-type liquid level probes, and gas and vacuum connections were also provided at the top of the tank. The unit was heated with eight $1000-\mathrm{w}$ strip heaters, mounted on the tank walls and attached with Wraplock steel bands. Several thermocouples were welded to the outer wall and one was located in a Thermowell in the salt. The tank was insulated with Fibrefrax insulation. The melt tank was prepared for service in accordance with the specifications described above in connection with the container system.

The ternary eutectic was prepared in a 347 S.S. tank of $\approx 3 \mathrm{ft}^{3}$ capacity (Figure 23 ). It consisted of a length of 12 -in.-IPS schedule 10 pipe welded to weld caps at each end for an over-all outside height of $4 \mathrm{ft}$. The vessel was equipped with a sightport and a 1/2-in.-IPS dip tube which cleared the bottom by $4 \mathrm{in}$. This clearance provided a sump for the collection of $\mathrm{MgO}$ and other insolubles that were observed to have settled when eutectic was prepared on a glass rack. ${ }^{19}$ A $35-\mu$, sintered 347 S.S. filter (Micro Metallic Corp.) was located in the transfer line outside the tank. Re- 


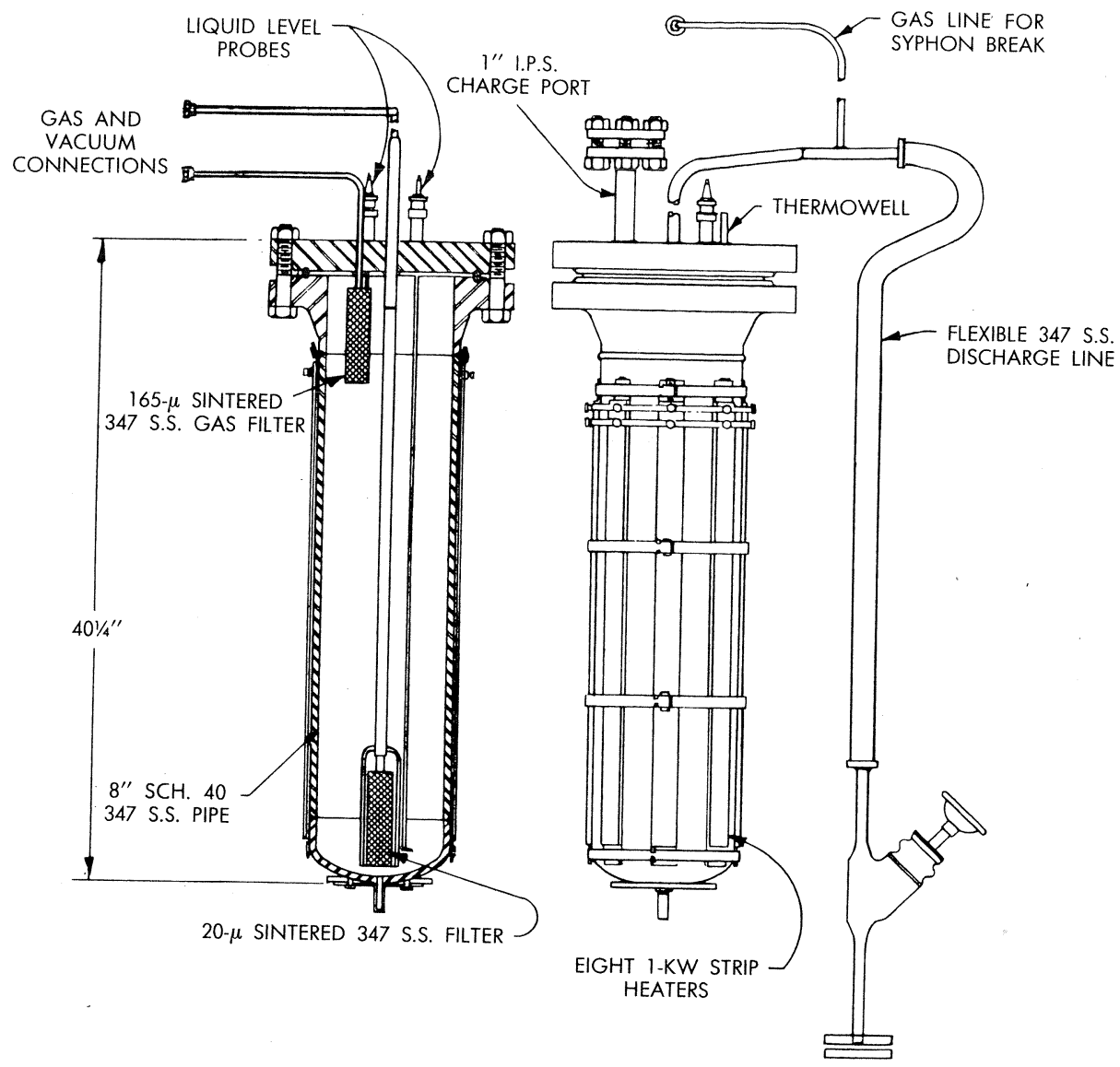

Figure 22. LiCl-KGl eutectic melt tank. (Material: type 347 S.S.; capacity $=0.87 \mathrm{ft}^{3}$.)

agents were charged at the top of the tank through a 4-in. flanged port which was provided with a water-cooled rubber O-ring seal. A $65-\mu$, sintered 347 S.S. filter (Micro Metallic Corp.) was located in the upper flange to prevent carry-over of reagent fines into the vacuum system before melting. Before the first charge was added, the melt tank was leak-tested and outgassed as described above in connection with the container system. The vessel was wrapped with three separate heater circuits for better temperature control, and an additional circuit was provided for the filter and transfer line. Six Chromel-Alumel thermocouples were welded to the outer wall of the melt tank for use in measuring and controlling the temperature of the salt.

A high speed, portable vacuum dolly was used in conjunction with the melt tank. It included two forepumps (Type 1402, Welch Scientific Co.) in parallel with a diffusion pump (Model McZ300-
011, Consolidated Vacuum Corp.), a by-pass system to prevent contamination of the diffusion pump oil, and two liquid nitrogen-cooled glass traps in series, all interconnected with 2-in. copper tubing. Consolidated Engineering Co. vacuum valves were used for shutoff service. The traps were suspended from stainless steel bellows at their inlet and outlet connections to minimize vibrations and shocks when the vacuum dolly was moved. The traps were enclosed in a Plexiglas housing as a safety measure. The traps were made of glass to permit visual inspection as the $\mathrm{HCl}$ and water vapor from the eutectic reagent mixture were condensed. Since it was not known at first whether all the vapors would condense in one trap, two units were installed, the intention being that after the first trap was filled with $\mathrm{HCl}$ and water, the liquid $\mathrm{N}_{2}$ would be removed and the trap heated, and the previously condensed vapors would then be distilled into the second trap and 


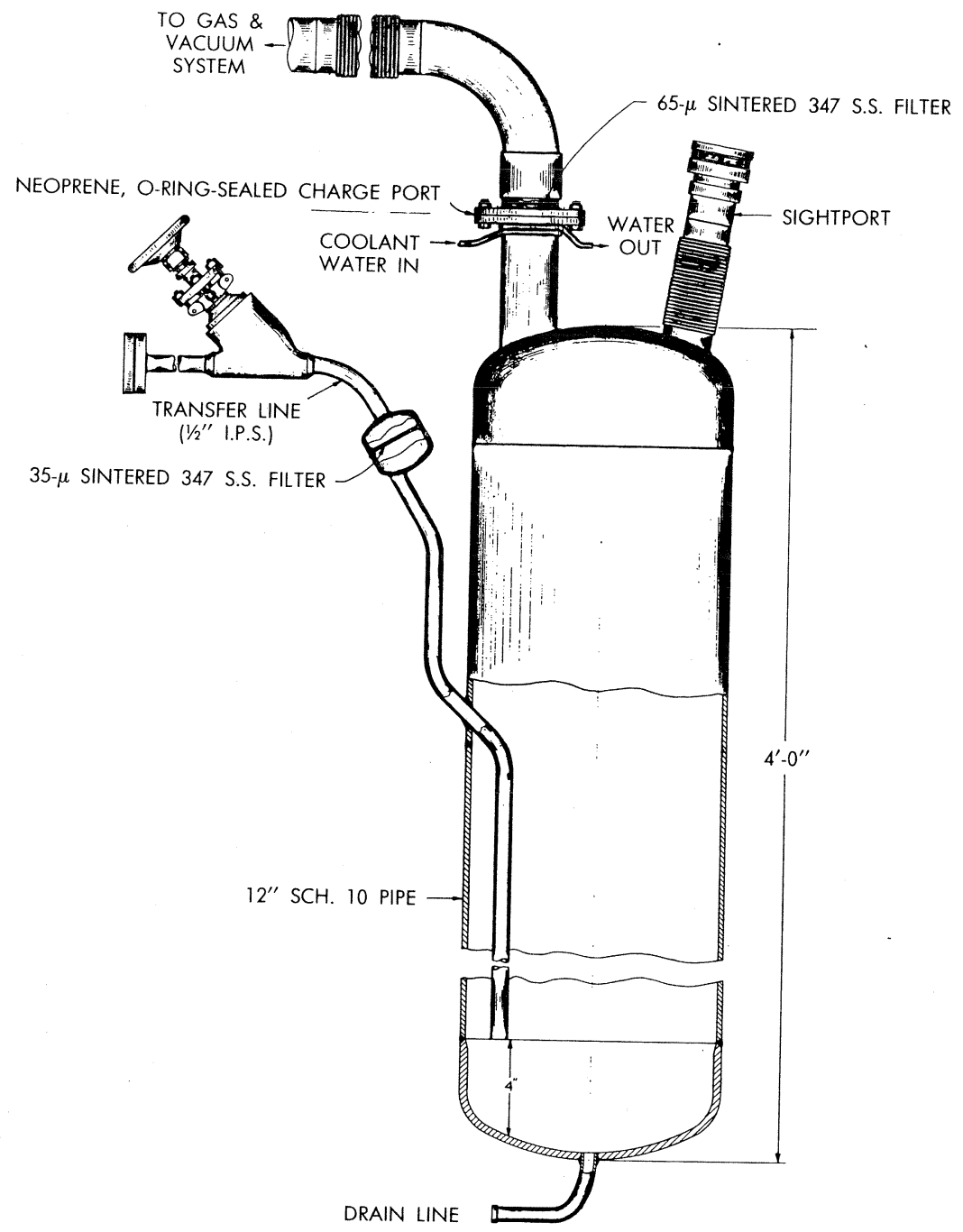

Figure 23. NaCl-KCl- $\mathrm{MgCl}_{2}$ eutectic melt tank. (Material: type $347 \mathrm{~S} . \mathrm{S}$.; capacity $=3 \mathrm{ft}^{3}$.)

condensed there. In actual practice, however, this procedure was not required.

Loading and Melting Procedures. Reagent grade $\mathrm{LiCl}$ and $\mathrm{KCl}$, obtained in 1-lb glass bottles from the Baker Chemical Co., were used to prepare the binary eutectic. Reagent grade $\mathrm{KCl}$ and $\mathrm{NaCl}$, also obtained in 1-lb glass bottles from the Baker Chemical Co., and anhydrous $\mathrm{MgCl}_{2}$ from the Carborundum Metals Co. were used to prepare the ternary eutectic. The $\mathrm{MgCl}_{2}$ was a byproduct from the preparation of $\mathrm{Ti}$ and $\mathrm{Zr}$, and was shipped in polyethylene-lined steel drums. The hard crystals had to be chipped out of the drum with a hammer and chisel and then further crushed with a steel mortar and pestle. A graywhite coating around the $\mathrm{MgCl}_{2}$ crystals, about 1 in. thick, was discarded after it was found to clog the frits when the eutectic was prepared in glass tubes on a vacuum rack.

The following procedures were used for preparing both the binary and ternary eutectics. ${ }^{20} \mathrm{~A}$ charge of 85 to $150 \mathrm{lb}$ of reagents was loaded into the melt tank through the charging port. To facilitate thorough mixing, they were added in alternating layers in the eutectic proportions until about six discrete layers of each were built up.

A 1-lb batch of eutectic was prepared on a vacuum rack and added to the salt mixture for the first charge to help melt the charge at a lower temperature by seeding. Subsequently, the tank was never completely emptied, and some eutectic was always retained for seeding new batches. 


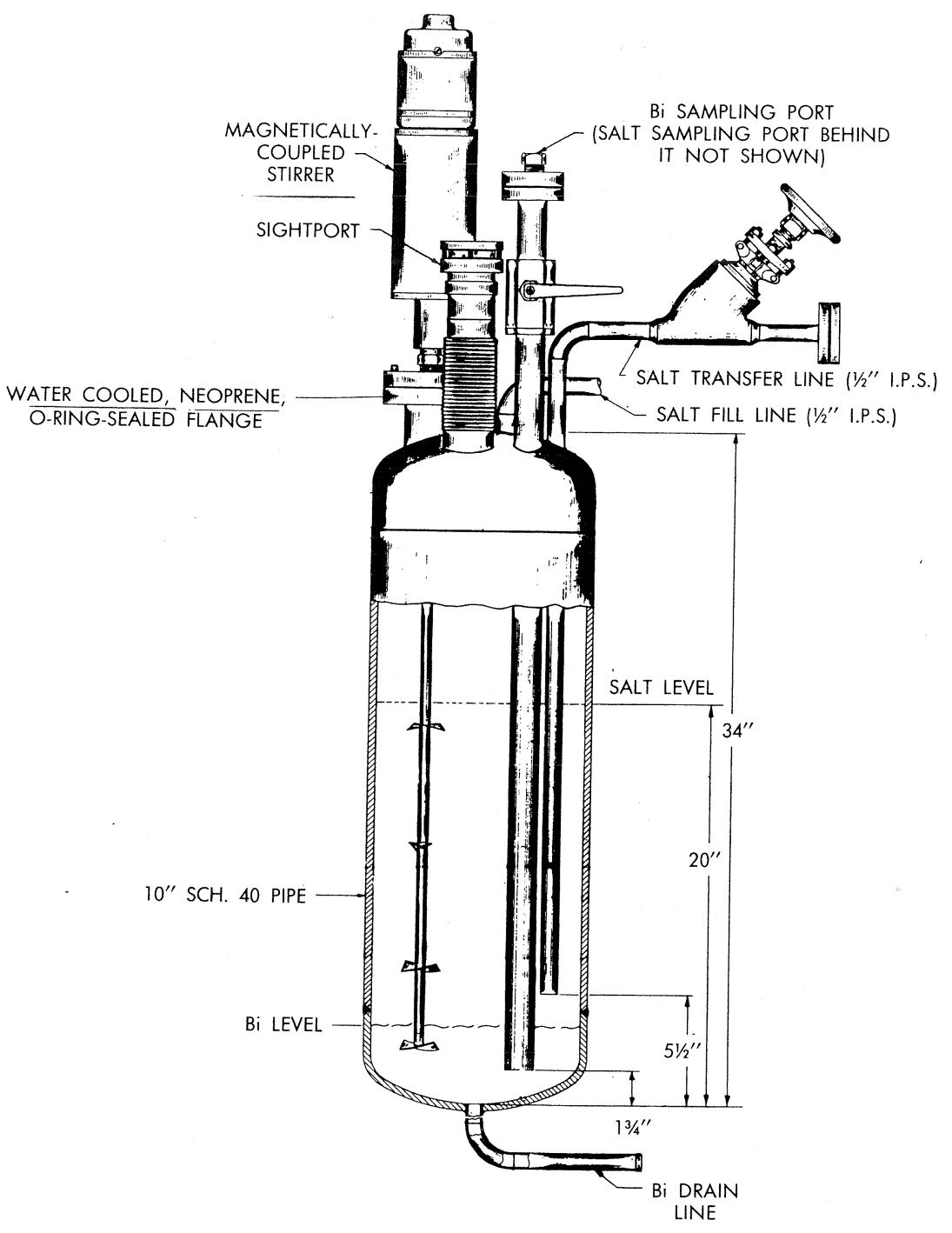

Figure 24. Eutectic pretreatment tank. (Material: type 347 S.S.; capacity $=0.12 \mathrm{ft}^{3} \mathrm{Bi}, 0.87 \mathrm{ft}^{3}$ salt.)

After charging, the melt tank was sealed and rechecked for leak tightness and then evacuated. When the pressure reached $20 \mu \mathrm{Hg}$, heat was applied at such a rate that the pressure in the tank did not rise above $30 \mu \mathrm{Hg}$. Heating was continued for 3 to 5 days, depending on the degree of dryness of the reagents. Most of the water was evolved at temperatures below $150^{\circ} \mathrm{C}$. When the temperature reached $500^{\circ} \mathrm{C}$, the salt was kept at this temperature for at least $24 \mathrm{hr}$ to ensure proper mixing. The tank was then filled with 1 atmosphere of $\mathrm{He}$ or Ar.

In the case of the ternary salt, before the reagents reached the eutectic melting point, the cold traps in the high speed vacuum system were re- moved and their contents examined. A 150-lb batch of salt usually produced 50 to $100 \mathrm{ml}$ of HCl.

Pretreatment Procedures. It was found in $\mathrm{Bi}$ salt equilibration studies ${ }^{17,21}$ that $\mathrm{U}$ and $\mathrm{Mg}$ were lost from the $\mathrm{Bi}$ when the $\mathrm{Bi}$ fuel solution containing $\mathrm{U}, \mathrm{Mg}$, and $\mathrm{Zr}$ was contacted with the binary or ternary eutectic that had been prepared by vacuum melting. These losses were believed to be due to oxidizing impurities present in the salt that were not removed during the initial preparation. The object of the pretreatment process was to remove these oxidizing impurities before using the salt in experiments. Although the impurities were probably not removed completely, pretreatment 
did greatly improve the stability of the $\mathrm{U}, \mathrm{Mg}$, and $\mathrm{Zr}$ additives in $\mathrm{Bi}$ when in contact with the fused salt.

Approximately $100 \mathrm{lb}$ of binary or ternary salt could be pretreated in the 34-in.-long, 10-in.-IPS, 347 S.S. tank (Figure 24). It consisted of a 2-ft length of pipe with weld caps at both ends and was mounted on a dolly to make it portable. The tank was wrapped with nichrome resistance heater wire, had 15 thermocouples welded along the outer wall for temperature control, and was insulated. The tank was prepared for service as described above in connection with the container system. On the top weld cap were mounted two $1 / 2$-in. pipes for filling and discharging the salt, two 1 -in.-IPS ports for sampling both $\mathrm{Bi}$ and salt, a 1/4-hp agitator, and a sightport. Each of the two salt lines was equipped with a 1/2-in.-IPS, Y-pattern, bellows-sealed globe valve and ring-type joint S.S. flanges and metallic rings. A seal-welded $1 / 2$-in.-IPS drain line for Bi was located on the bottom weld cap.

Each sampling port was equipped with an air lock consisting of a Jamesbury ball valve and a Wilson-type compression seal. The two air locks were connected with $3 / 8$-in. S.S. tubing and two Imperial diaphragm valves in such a manner that either air lock could be operated separately when the manifold was connected to an available vacuum and inert gas supply.

Four sets of propeller blades mounted on an $\approx 30$-in.-long shaft were used to agitate the salt and Bi mixture at $2000 \mathrm{rpm}$. Three sets of $1 / 16$-in.thick blades, made from $3 / 4 \times 1 \frac{1}{1 / 2}$-in. 347 S.S. strip and pitched at about $20^{\circ}$, were in the salt phase, and the fourth was in the $\mathrm{Bi}$. A variable speed motor was magnetically coupled to the stirrer shaft (Figure 15). The agitator mounting flange on the tank was water-cooled to protect the Neoprene O-ring seal at the elevated temperatures.

The pretreatment procedure was as follows. A 34,300 -g charge of $\mathrm{Bi}$ was vacuum melted and filtered in 1500 -g batches on a glass rack to remove most of the impurities and then cast in Pyrex tubes. After the glass was broken away, the Bi was rinsed with acetone and charged to the pretreatment tank through the salt sampling port. The Bi charge was then melted under vacuum and held at $500^{\circ} \mathrm{C}$. Additions of $5000 \mathrm{ppm} \mathrm{Mg}, 250 \mathrm{ppm}$ $\mathrm{Zr}$, and 1000 ppm U were made. The $\mathrm{Zr}$ was added to inhibit corrosion of the container, and both $\mathrm{Mg}$ and $\mathrm{U}$ served to reduce the oxidizing impuri- ties in the salt. After the melt was sampled to determine whether the expected additive concentrations had been obtained, the pretreatment tank fill line was connected to the dip tube of the melt tank with a $1 / 2$-in. S.S. pipe insert and ring-type joint S.S. flanges. The section of the transfer line between the melt tank and the pretreatment tank valves was evacuated by means of an uninsulated $1 / 4$-in. S.S. tube welded into the transfer line. This tube was water-cooled $\approx 1 \mathrm{ft}$ above the joint to freeze any salt entering it during the transfer. The transfer lines were wrapped with heater wire, insulated, and heated until the lowest temperature was above $500^{\circ} \mathrm{C}$.

Salt was transferred by pressurizing the melt tank with 5 psig He while maintaining the pretreatment tank at a pressure of 0 psig. The melt tank salt discharge valve and then the pretreatment tank fill line valve were opened. Salt flow was controlled by varying the pressure in the melt tank. The salt level in the pretreatment tank was observed through the sightport, and the final level was determined with a preset resistance-type liquid level probe. When the pretreatment tank was full, the transfer line was purged with inert gas to blow back any salt to the melt tank; then the two valves were closed and the transfer line was allowed to cool. The pretreatment tank was pressurized with 5 psig Ar, and the stirrer was turned on and operated at $2000 \mathrm{rpm}$. Agitation was very effective, since it was possible to observe through the sightport that small $\mathrm{Bi}$ particles were circulated through the salt. The pretreatment process was carried out for at least three weeks, but no attempt was made to establish the optimum length of time required.

Samples of salt and $\mathrm{Bi}$ were taken to determine the $\mathrm{U}$ concentration in the salt and $\mathrm{Bi}$ and the $\mathrm{Mg}$ and $\mathrm{Zr}$ concentrations in the $\mathrm{Bi}$. The U concentration in the salt phase never exceeded $1 \mathrm{ppm}$ at the end of the pretreatment. The actual Mg loss in the $\mathrm{Bi}$ could not be detected since it would have fallen within the scatter of the analytical results. It should be noted that there was some $\mathrm{Zr}$ loss in the tank during pretreatment of three batches. Because of its relatively low solubility in $\mathrm{Bi}$, the $\mathrm{Zr}$ was thought to have precipitated at a cold spot in the Bi drain line.

\section{Salt Transfer to Experimental Equipment}

Small-Scale Equipment. When small batches of eutectic were required, as in corrosion experi- 
ments and in Bi-salt equilibration studies, it was found that the salt could best be handled in Precision-bore Pyrex tubing.

The procedure for filling these tubes was as follows (Figure 25). The tubes were first capped with rubber stoppers, outgassed with a propane hand torch to a pressure of $\approx 1 \mu \mathrm{Hg}$, the gases being exhausted through the side connection, and then filled with Ar. Each tube was then uncovered and placed underneath the loosely fitting endcap on the salt treatment tank transfer line. During the transfer operation, a flow of He was provided through a connection at the endcap and a flow of Ar at the tube mouth. The utilization of two inert gases, one lighter and the other heavier than air, in this manner tended to minimize the possibility of contaminating the tube surfaces or the flowing salt with air. When the pretreatment tank was

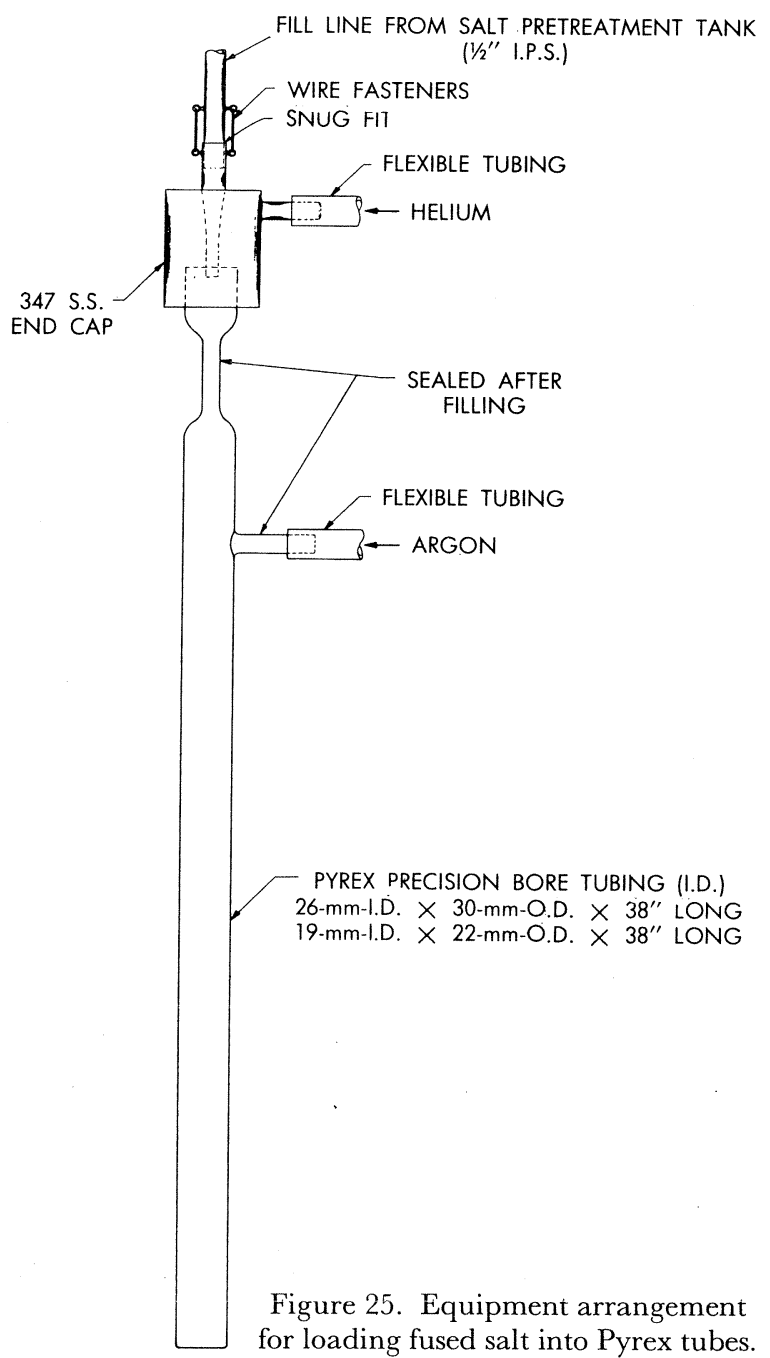

pressurized with Ar, the salt flowed into the Pyrex tube. After the tube was filled, it was sealed at the neck, and the Tygon tubing through which the Ar was supplied was clamped off and cut. Only clean pretreated salt, a perfectly colorless and transparent liquid (and milky-white and opaque solid) was used. If the transferred salt appeared to be discolored in any way, or if the solution was cloudy, it usually indicated that air leakage and container corrosion had occurred. In this case, the salt was discarded.

The salt was transferred from the Precision-bore tubing as follows. The tube was first inserted through an O-ring compression seal which con-

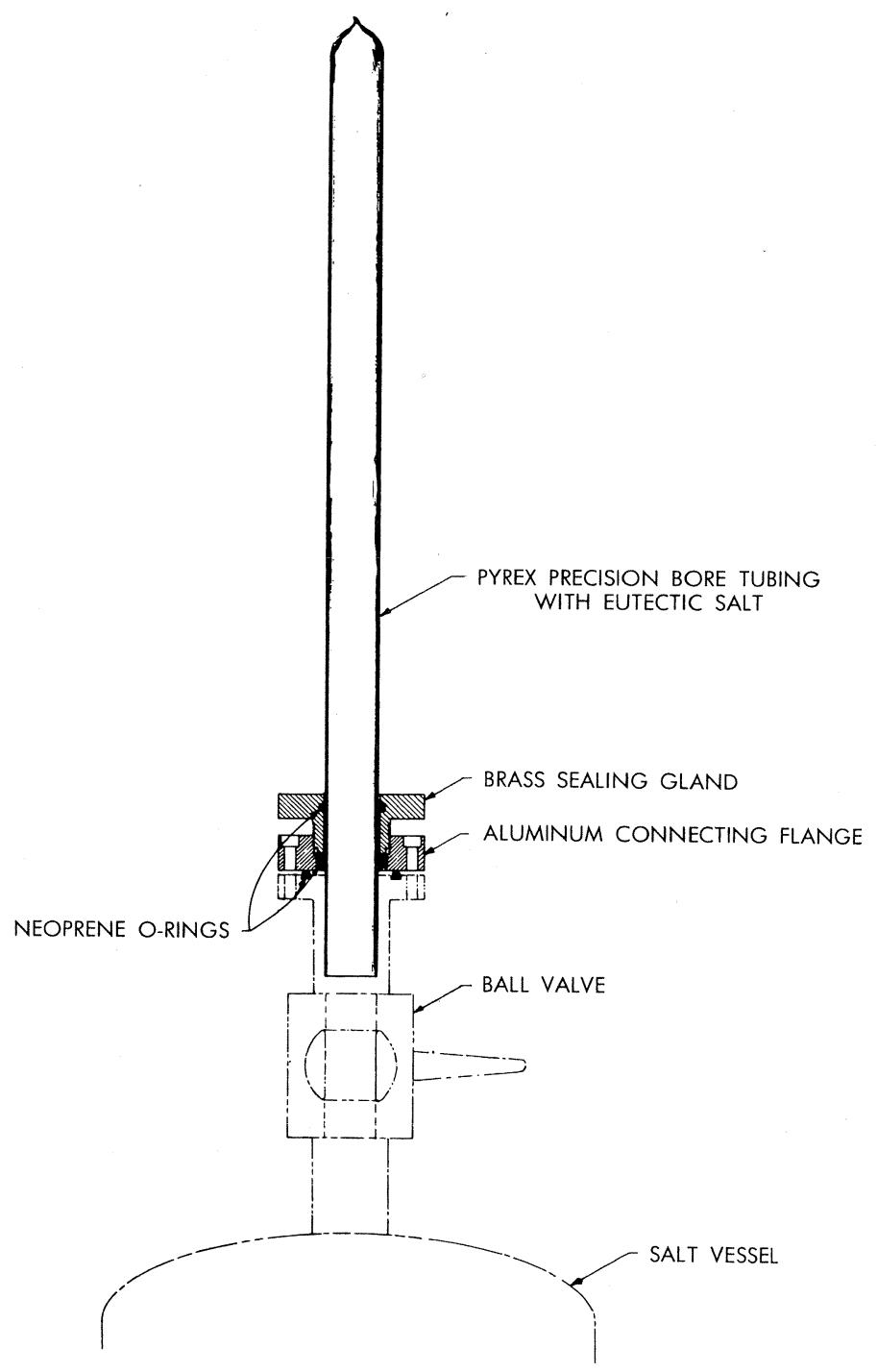

Figure 26. Equipment arrangement for discharging salt from Pyrex tubes. 
sisted of a large brass gland nut mounted in the center of an aluminum flange. The gland nut was used to tighten Neoprene O-rings against the glass tube (Figure 26). The bottom of the tube was then broken away and any exposed salt resulting from this operation was likewise discarded before the whole assembly was connected to the mating flange of an air lock. In this manner, exposure of even a very small salt area to air was minimized. After the compression seal and flanges were checked for leak tightness, the air lock was evacuated and purged with $\mathrm{He}$ at least three times, very slowly so that salt movement would be minimized. Thereafter, the pressures in the air lock and apparatus were equalized and the intervening ball valve opened. Often the salt was resting on the ball valve and slid into the vessel when the valve was opened. Otherwise, a tap with a wooden mallet caused the salt to slide into the vessel. The ball valve was then closed.

Loops. Large equipment, such as loops, was charged with salt directly by connecting the pretreatment tank to the experimental equipment with 347 S.S. pipe and flanges. The salt was transferred by pressurizing the pretreatment tank with $\mathrm{He}$ or Ar, by a procedure similar to that described above for transferring salt from the melt tank to the pretreatment tank.

\section{PREPARATION OF $\mathrm{BiCl}_{3}$}

The use of $\mathrm{BiCl}_{3}$ as an oxidizing agent in the LMFR fuel processing system was proposed by Dwyer ${ }^{22}$ in 1955 . Although the $\mathrm{BiCl}_{3}$ is very corrosive in the common metal systems, ${ }^{7}$ it can be contained in Pyrex. Furthermore, it has been found in other work at Brookhaven ${ }^{23}$ that when $\mathrm{U}, \mathrm{Mg}$, $\mathrm{Zr}$ and other solutes were present in $\mathrm{Bi}$ in stoichio- metric excess of $\mathrm{BiCl}_{3}$, these fuel solutes were oxidized and not the container material. This has been found to be the case in repeated bench-scale equilibration experiments involving 347 S.S. and Mo containers.

Reagent grade $\mathrm{BiCl}_{3}$ from the General Chemical Company and Baker Chemical Company has been used. It is associated with large quantities of water which must be removed before the $\mathrm{BiCl}_{3}$ can be used in experimentation. The $\mathrm{BiCl}_{3}$ hydrolyzes to $\mathrm{BiOCl}$ and $\mathrm{HCl}$ in the presence of water, and any attempt to dry the material which involves the removal of $\mathrm{HCl}$ will result in the formation of BiOCl. The purification method found satisfactory involved vacuum drying the reagent grade $\mathrm{BiCl}_{3}$ and subsequent sublimation to separate it from the $\mathrm{BiOCl}$.

The $\mathrm{BiCl}_{3}$, in 100 to 200 -g batches, was first dried under vacuum at $100^{\circ} \mathrm{C}$ in a Pyrex drying tube. It was then melted and filtered through a $50-\mu$ Pyrex frit. Varying quantities of BiOCl residue were removed in this step. The solid filtrate was then charged into cup " $A$ " of the sublimation apparatus shown in Figure 27, covered with a wad of Pyrex wool to prevent particle entrainment during sublimation, and heated to $200^{\circ} \mathrm{C}$. The sublimate was condensed on the water-cooled condenser "B" at a system pressure of 1 to $5 \mu \mathrm{Hg}$. About half the charge was allowed to sublime, the rest being discarded. The tube containing the residue was then cooled, and the condenser was heated under a $\mathrm{He}$ pressure of $5 \mathrm{in}$. $\mathrm{Hg}$, to allow the sublimate to melt into the receiver flask "D." The condenser and receiver were sealed off and separated at point "C." The receiving tubes "E," which had been previously calibrated, could then be filled with known volumes of $\mathrm{BiCl}_{3}$ and sealed off.

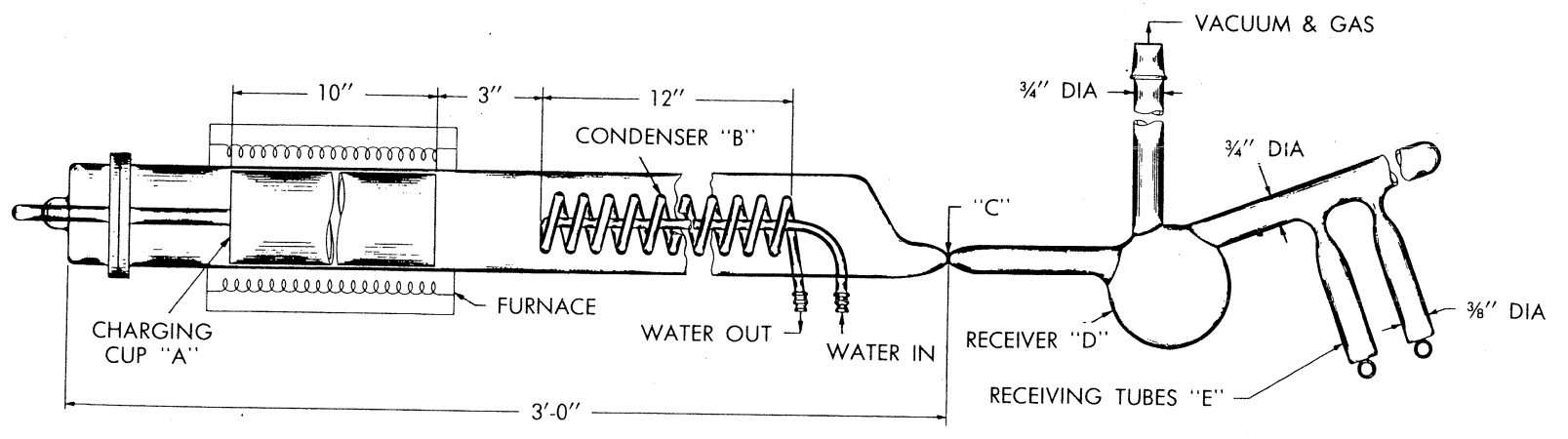

Figure 27. $\mathrm{BiCl}_{3}$ purification apparatus. 


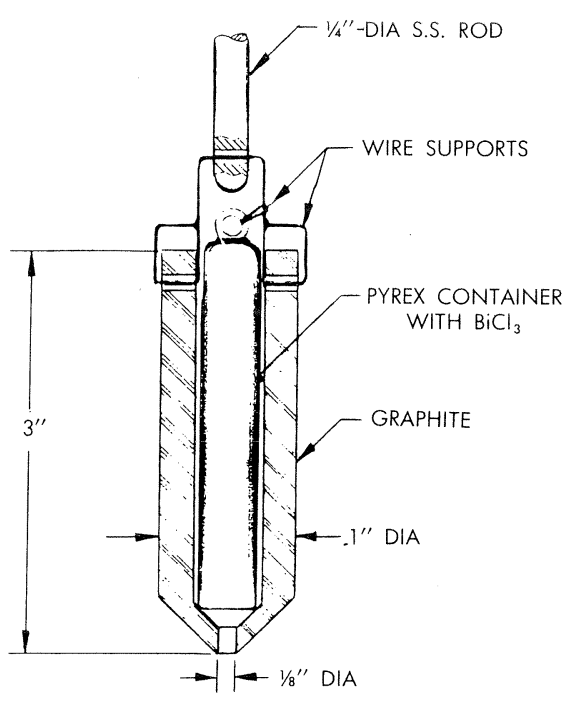

Figure 28. Basket arrangement for adding $\mathrm{BiCl}_{3}$ to fused salt.

With this apparatus it was possible to prepare 50 to 100 -g quantities of purified $\mathrm{BiCl}_{3}$. It may be more desirable to prepare larger quantities of $\mathrm{BiCl}_{3}$ in the future by drying the reagent grade material with hydrogen chloride, but no work was done on this procedure at Brookhaven.

Another method also uscd successfully involved a much simpler apparatus than the one shown in Figure 27. The $\mathrm{BiCl}_{3}$ was allowed to condense directly on the wall at one end of a Pyrex tube which was cooled with an air blower. The condensed $\mathrm{BiCl}_{3}$ was subsequently heated and transferred to receiving tubes as before.

The sealed, $\mathrm{BiCl}_{3}$-filled capsules could be stored indefinitely. When small quantities of $\mathrm{BiCl}_{3}$ were to be added to the fused salt, a capsule was selected and weighed. The top of the capsule was then broken off and the capsule inverted and placed into a graphite basket (Figure 28) as a precautionary measure. (During early attempts to add $\mathrm{BiCl}_{3}$ to molten salt directly from Pyrex capsules, it was found difficult to support them directly from a metal rod, and at times the capsules cracked from the thermal stress.) The basket was lowered through the Wilson-type compression seal and air lock arrangement into the experimental apparatus. When the basket reached the heated gas space above the salt, the $\mathrm{BiCl}_{3}$ melted and was forced out of the tube by its own vapor pressure. The liquid $\mathrm{BiCl}_{3}$ drained through a hole in the graphite basket.

\section{PHYSICAL PROPERTIES OF THE SALTS}

Several of the more important physical properties of the two eutectics have been determined experimentally at Brookhaven and elsewhere. These have included the density, viscosity, surface tension, interfacial tension with $\mathrm{Bi}$, and specific heat of both the LiCl-KCl binary eutectic and the $\mathrm{NaCl}-\mathrm{KCl}-\mathrm{MgCl}_{2}$ ternary eutectic, and the thermal conductivity and enthalpy of the former. It has been difficult to obtain accurate measurements on these salts because they are highly reactive and therefore the work has had to be done under inert and leak-tight conditions as well as at high temperatures.

\section{Binary Eutectic}

The density of the binary salt was measured by Dworkin et al. at ORNL ${ }^{24}$ and by Berkowitz at Brookhaven. ${ }^{25}$ The Oak Ridge data varied from $1.67 \mathrm{~g} / \mathrm{cc}$ at $400^{\circ} \mathrm{C}$ to 1.57 at $600^{\circ} \mathrm{C}$, and the results can be described by the equation

$$
\rho=1.8885-0.527 \times 10^{-3} \mathrm{~T}
$$

for the range $380^{\circ}$ to $600^{\circ} \mathrm{C}$, where $\rho$ is the density in $\mathrm{g} / \mathrm{cc}$ and $T$ the temperature in ${ }^{\circ} \mathrm{C}$. The Brookhaven data deviated by a maximum of $1 \%$ from these results.

Viscosity measurements on the binary salt were made by Weisman at Brookhaven ${ }^{26}$ and by Bonilla at Columbia University ${ }^{27}$ using capillary viscometers. The data from the two laboratories appear to be in fairly good agreement. The viscosity determined at Brookhaven varied from 2.4 $\mathrm{cp}$ at $510^{\circ} \mathrm{C}$ to 5.3 at $385^{\circ}$, and over this temperature range the data are best represented by

$$
\log \mu=(1500 / T)-1.56
$$

where $\mu$ is the viscosity in centipoises and $T$ the temperature in ${ }^{\circ} \mathrm{K}$. The values found by Bonilla were $2.25 \mathrm{cp}$ at $510^{\circ} \mathrm{C}$ and 5.22 at $384^{\circ}$, and his data fell on a line parallel to that of Weisman but $5 \%$ lower.

Shaikhmahmud and Bonilla ${ }^{28}$ measured the surface tension of the binary salt against air in a capillary apparatus at $432.2^{\circ} \pm 5.5^{\circ} \mathrm{C}$. They obtained a value of 118.2 dynes/cm from three groups of three drops each with an average deviation of $0.7 \%$. They also investigated the interfacial tension between $\mathrm{LiCl}-\mathrm{KCl}$ and molten $\mathrm{Bi}$ in the same capillary drop-weight apparatus in the temperature range $371^{\circ}$ to $482^{\circ} \mathrm{C}$. A large number 
of results were obtained at $432.2^{\circ} \pm 5.5^{\circ} \mathrm{C}$ with an average value of $240.0 \pm 5.8 \mathrm{dynes} / \mathrm{cm}$. Subsequent values were computed at $371^{\circ}$ and $482^{\circ} \mathrm{C}$, and an average value of 240.3 dynes/cm was obtained for this range, which shows that there was no measurable temperature dependence. The value computed from Antonoff's rule (i.e., that the interfacial tension is equal to the difference in surface tensions between the individual liquids), with the values $\sigma_{\mathrm{Bi}}=368.0$ dynes $/ \mathrm{cm}$ and $\sigma_{\mathrm{LiCl}-\mathrm{KCl}}$ $=118.2$ used, was 249.8 dynes $/ \mathrm{cm}$ or $4 \%$ higher than the experimental value at $426^{\circ} \mathrm{C}$.

Ellis ${ }^{29}$ reported good agreement with the above interfacial tension data. Using an apparatus based on Latin's technique (Trans. Faraday Soc. 34, 1384, 1938 ) and estimating the accuracy as $\pm 10 \%$, he obtained values of $267 \mathrm{dynes} / \mathrm{cm}$ at $530^{\circ} \mathrm{C}$ and 265 at $450^{\circ}$. No temperature dependence was observed.

Shaikhmahmud and Bonilla ${ }^{28}$ also computed a maximum spreading coefficient of the binary salt on molten $\mathrm{Bi}$ of +10 dynes $/ \mathrm{cm}$. Under static conditions, therefore, no appreciable spreading should occur. This was the case for the single experiment in which molten salt contacted molten $\mathrm{Bi}$ in a sealed $304 \mathrm{~S} . \mathrm{S}$. tube at $426^{\circ} \mathrm{C}$.

The thermal conductivity of the binary eutectic was measured by Deem ${ }^{30}$ by the steady-heat-flow method. Only two values, 0.0060 and $0.0063 \mathrm{cal} /$ sec-cm- ${ }^{\circ} \mathrm{C}\left(1.448\right.$ and $\left.1.520 \mathrm{Btu} / \mathrm{hr}-\mathrm{ft}-{ }^{\circ} \mathrm{F}\right)$ were obtained at a mean temperature of $510^{\circ} \mathrm{C}$. The absolute error was estimated to be possibly as high as $\pm 25 \%$.

The enthalpy of the LiCl-KCl salt was measured by Powers and Blalock at ORNL ${ }^{31}$ and by Douglas and Dever at the Bureau of Standards ${ }^{32}$ by the ice-calorimeter method. The Oak Ridge results, based on 97 determinations for liquid and 10 determinations for solid salt, were

$$
\begin{gathered}
H_{T}(\text { liq })-H_{0^{\circ} \mathrm{C}}(\text { sol })=30+0.32(5) \mathrm{T} \\
\text { between } 351^{\circ} \text { and } 840^{\circ} \mathrm{G}
\end{gathered}
$$

and

$$
\begin{gathered}
H_{T}(\mathrm{sol})-H_{0^{\circ} \mathrm{C}}(\mathrm{sol})=4+0.23(6) \mathrm{T} \\
\text { between } 97^{\circ} \text { and } 351^{\circ} \mathrm{C}
\end{gathered}
$$

where $H$ is the enthalpy in cal/g and $T$ is the temperature in ${ }^{\circ} \mathrm{C}$. The heat of fusion was $\approx 64 \mathrm{cal} / \mathrm{g}$.

The Bureau of Standards work was more precise, and a smoothed enthalpy equation was derived for the liquid binary in the range $351^{\circ}$ to $800^{\circ} \mathrm{C}$ as follows:

$$
\begin{gathered}
H_{T}-H_{0^{\circ} \mathrm{C}}=84.40+1.464619 T- \\
1.88286 \times 10^{-4} T^{2}+5.6336 \times 10^{-8} T^{3}
\end{gathered}
$$

where $\mathcal{T}$ is the temperature in ${ }^{\circ} \mathrm{C}$ and $H$ is the enthalpy in absolute joules/g. The enthalpy is relative to that of the crystalline eutectic at $0^{\circ} \mathrm{C}$, and each value includes the heats of fusion of the two component salts and the heat effect resulting from the mixing of the two liquid salts at the eutectic temperature $\left(351^{\circ} \mathrm{G}\right)$. It was also possible to determine the heat capacity and its variation with temperature. These results are best represented by

$$
\begin{gathered}
C_{p}=1.4653-3.77 \times 10^{-4} \mathrm{~T}+1.69 \times 10^{-7} \mathrm{~T}^{2} \\
\text { between } 351^{\circ} \text { and } 800^{\circ} \mathrm{C}
\end{gathered}
$$

where $C_{p}$ is the heat capacity in absolute joules/g${ }^{\circ} \mathrm{C}$ and $\mathrm{T}$ is the temperature in ${ }^{\circ} \mathrm{C}$. The estimated uncertainty is between 0.5 and $1 \%$.

\section{Ternary Eutectic}

Molino ${ }^{33}$ measured the density of the ternary salt at Brookhaven and found that it varied from $1.90 \mathrm{~g} / \mathrm{cc}$ at $420^{\circ} \mathrm{C}$ to 1.75 at $610^{\circ}$. In that range, the results are best described by

$$
\rho=2.226-0.778 \times 10^{-3} \mathrm{~T}
$$

where $\rho$ is the density in $\mathrm{g} / \mathrm{cc}$ and $T$ is the temperature in ${ }^{\circ} \mathrm{C}$.

Molino $^{33}$ also measured the viscosity of the ternary salt at Brookhaven in the range $400^{\circ}$ to $550^{\circ} \mathrm{C}$. It varied between 4.64 and $2.14 \mathrm{cp}$; over this range, the results are best described by

$$
\log \mu=(3040 / T)-2.96
$$

where $\mu$ is the viscosity in centipoises and $T$ is the temperature in ${ }^{\circ} \mathrm{K}$.

The surface tension of the salt was accurately measured by Ellis, ${ }^{34}$ who found that it can be represented by

$$
\sigma=113.1-4.31 \times 10^{-2} \mathcal{T}
$$

between $450^{\circ}$ and $600^{\circ} \mathrm{C}$

where $\sigma$ is the surface tension in dynes/cm and $T$ is the temperature in ${ }^{\circ} \mathrm{C}$. The standard deviation of the experimental points from the least-squares line was 2.7 dynes $/ \mathrm{cm}$.

Ellis $^{35}$ also calculated the interfacial tension between the molten ternary salt and molten $\mathrm{Bi}$ from Antonoff's rule. He used values for the surface tension of Bi from the Liquid Metals Handbook (NAV EXOS P-733, Rev.) and interpolated between re- 
sults presented by O.G. Desyatnikov (Zhur. Priklad. Khim. 29, 870, 1956) for various $\mathrm{MgCl}_{2}, \mathrm{NaCl}$, and $\mathrm{KGl}$ mixtures to obtain the surface tension of the ternary eutectic. These calculations yielded the following:

$400^{\circ} \mathrm{C} \quad 450^{\circ} \mathrm{C} \quad 500^{\circ} \mathrm{C} \quad 550^{\circ} \mathrm{C}$

$\begin{array}{lrrrr}\sigma_{\mathrm{Bi}} & 371 & 367 & 363 & 359 \\ \sigma_{\mathrm{Sa} 1 \mathrm{t}} & 96 & 94 & 92 & 90 \\ \text { Interfacial tension } & 275 & 273 & 271 & 269\end{array}$

His experimentally determined values were 270 and 246 dynes $/ \mathrm{cm}$ at $535^{\circ}$ and $492^{\circ} \mathrm{C}$, respectively. These showed good agreement (within 10\%) with the calculated values.

In a salt corrosion study ${ }^{7}$ conducted at Brookhaven, no ternary salt was found between the $\mathrm{Bi}$ and the container interface in tilting furnace capsule tests at temperatures of $450^{\circ}$ to $500^{\circ} \mathrm{C}$. This suggests that creep of salt along these interfaces should not be expected.

No experimentally determined values for the thermal conductivity of the ternary salt are available. However, the empirical method described by Gambill ${ }^{36}$ might be suitable for calculating values of conductivity.

The enthalpy and specific heat of the ternary salt have not been experimentally determined. A specific heat of $0.25 \mathrm{cal} / \mathrm{g}-{ }^{\circ} \mathrm{C}$ was calculated by use of T.B. Douglas's correlations. ${ }^{32}$

\section{ACKNOWLEDGMENTS}

The authors gratefully acknowledge the contributions of the following Brookhaven National Laboratory staff members: D.W. Bareis, who initiated the earliest phases of the fused salt work, and F.B. Hill, under whose supervision most of the later work was done; C.H. Waide and J. Weisman, who helped design and build the early experimental equipment; R.J. Isler, whose section operated the Salt Components Test Loop (Loop M); W.W. Becker, J.H. Klein, and G.A. Schoener, who aided in the construction and operation of loops and other equipment; E. Kovacic, who helped devise the procedures for preparing and handling salt in large batches; R. Veverka, who helped develop and construct the in-line sampler, and L. Green, who tested it; and L.E. Kukacka, who helped design and test some of the components. Special thanks are due O.E. Dwyer for his guidance during all phases of the work.

\section{REFERENCES}

1. D.W. Bareis, A Continuous Fission Product Separation Process, LFR-3, BNL 125, July 1951, Declassified March 1957.

2. O.E. Dwyer, A.M. Eshaya, and F.B. Hill, Continuous removal of fission products from uranium-bismuth reactor fuels, Proc. 2nd UN Intern. Conf. on Peaceful Uses of Atomic Energy, Vol. 17, pp. 428-37, UN, Geneva, 1958.

3. R.H. Wiswall, The Distribution of Elements in Salt-Metal Systems With Special Reference to the Work of D.W. Bareis, LMFR-6, BNL 201, Sept. 1952, Declassified March 1957.

4. D.W. Bareis, R.H. Wiswall, and W.E. Winsche, Fused salts for removing fission products from U-Bi fuels, Nucleonics 12, No. 7, 16-19, (1954).

5. R.H. Wiswall, J.J. Egan, W.S. Ginell, F.T. Miles, AND J.R. Powell, Recent advances in the chemistry of liquid metal fuel reactors, Proc. 2nd UN Intern. Conf. on Peaceful Uses of Atomic Energy, Vol. 17, pp. 421-7, UN, Geneva, 1958.

6. Report of the Fluid Fuel Reactors Task Force to the Division of Reactor Development, US AEC, TID-8507, Feb. 1959.

7. H. Susskind, F.B. Hill, L. Green, S. Kalish, L.E. Kukacka, W.E. McNulty, and E. Wirsing Jr., Corrosion Studies for a Fused Salt-Liquid Metal Extraction Process for the Liquid Metal Fuel Reactor, BNL 585 (T164), June 1960.

8. L.E. KuKACKA, Unpublished work, BNL, Oct. 29, 1958.

9. W.E. MaNulty, Ch.E. Memorandum 399, BNL, Sept. 8, 1959.

10. A. Oltmann, Magnetic couplings for totally sealed systems, Proc. 7th Hot Labs. and Equipment Conf., A pril 7-9, 1959, pp. 229-31.

11. W.E. MaNulty, Memorandum, BNL, Dec. 23, 1958.

12. L. Green, Ch.E. Memorandum 186, BNL, May 5, 1958.

13. B. Kropp, Ch.E. Memorandum 094, BNL, Nov. 14, 1957.

14. C. J. Raseman and J. Weisman, Liquid Metal Fuel Reactor (LMFR) Processing Loops, Part I, BNL 322 (T-55), June 1954.

15. G. J. Raseman, H. Susskind, and G.H. Waide, Liquid Metal Fuel Reactor In-Pile Fuel Processing Loop (Loop B), LMFR-13, BNL 403 (T-88), Jan. 1957.

16. L.E. Kukacka, Ch.E. Memorandum 215, BNL, June 25, 1958.

17. C. J. Raseman, R. Bauman, and J. Weisman, Liquid Metal Fuel Reactor Fuel Processing Studies, LMFR-9, BNL 345, Jan. 1955, Declassified April 1957.

18. W.S. Ginell, Oxidative extraction of lanthanide metals from molten bismuth by fused salts, Ind. Eng. Chem. 51, 185 (1959).

19. L. Doyle, Extraction of Cerium From Bismuth-UraniumMagnesium by Treatment With Fused $\mathrm{MgCl}_{2}-\mathrm{NaCl}-\mathrm{KCl}$ Eutectic, Unpublished Brookhaven Report, 1956.

20. G. Farber and E. Kovacic, Memorandum, BNL, Feb. 16, 1956.

21. E. Kovacic, Summary Report of Bench Contactor Work up to December 1956, Unpublished Brookhaven Report, Sept. 12, 1957. 
22. O.E. Dwyer, Process for fission product removal from U-Bi reactor fuels by use of fused salt extraction, A.I. Ch. E. Journal 2, 163-8 (1956).

23. F.J. Salzano and F.B. Hill, Distribution of $U, Z r$, and $\mathrm{Ce}$ Between Molten Bi-Mg and Fused $\mathrm{NaCl}-\mathrm{KCl}-\mathrm{MgCl}_{2}$, BNL 639 (T-201) (in preparation).

24. A.S. Dworkin, F. J. Miller, D. J. Sasmor, I.S. Yaffe, and E.R. Van Artsdalen, Chemistry Division Semiannual Progress Report for Period Ending December 20, 1953, ORNL-1674, pp. 21-5.

25. J. Berkowitz, Memorandum, BNL, March 1952.

26. J. Weisman, Memorandum, BNL, April 17, 1953.

27. C.F. Bonilla, Mass Transfer in Liquid Metal and Fused Salt Systems, Columbia University Progress Report, Sept. 1, 1953, NYO-3094.

28. N.S. Shaikhmahmud and G.F. Bonilla, Interfacial Tensions of Molten Metal - Molten Salt Systems, Columbia University, June 1, 1953, NYO-3093.
29. R.B. Ellis, Southern Research Institute, Private communication to. F. Maslan, Feb. 12, 1959.

30. H.W. Deem, Battelle Memorial Institute, Private communication to O.E. Dwyer, Dec. 10, 1953.

31. W.D. Powers and G.C. Blalock, Enthalpy and Heat Capacity of LiCl-KCl Eutectic, ORNL-CF-53-8-30, Aug. 5, 1953.

32. T.B. Douglas and J.L. Dever, Heat Capacity of the Eutectic Mixture of LiCl-KCl From the Eutectic Temperature to $800^{\circ} \mathrm{C}$, NBS Report 2303, Feb. 20, 1953.

33. D. Molino, BNL, Private communication to O.E. Dwyer, Aug. 23, 1955.

34. R.B. Ellis, Southern Research Institute, Private communication to F. Maslan, June 24, 1959.

35. R.B. Ellis, Southern Research Institute, Private communication to F. Maslan, Feb. 2, 1959.

36. W.R. Gambill, Fused salt thermal conductivity, Chem. Eng. 66, 129-30 (1959). 